\title{
El ave como cielo: la presencia del ave chan en las bandas celestes mayas
}

L'oiseau comme "image » du ciel : la présence de l'oiseau chan dans les bandes célestes mayas

The bird as "image" of the sky: the presence of the chan bird in the Mayan celestial bands

\section{Rogelio Valencia Rivera y Daniel Salazar Lama}

\section{(2) OpenEdition}

\section{Journals}

Edición electrónica

URL: https://journals.openedition.org/jsa/15136

DOI: 10.4000/jsa. 15136

ISSN: 1957-7842

\section{Editor}

Société des américanistes

Edición impresa

Fecha de publicación: 15 diciembre 2017

Paginación: 9-45

ISSN: 0037-9174

\section{Referencia electrónica}

Rogelio Valencia Rivera y Daniel Salazar Lama, «El ave como cielo: la presencia del ave chan en las bandas celestes mayas», Journal de la Société des américanistes [En línea], 103-2 | 2017, Publicado el 15 diciembre 2017, consultado el 26 septiembre 2022. URL: http://journals.openedition.org/jsa/15136 ; DOI: https://doi.org/10.4000/jsa.15136 


\title{
El ave como cielo: la presencia del ave chan en las bandas celestes mayas
}

\author{
Rogelio Valencia Rivera y Daniel Salazar Lama*
}

\begin{abstract}
Dentro de la tradición plástica maya, el empleo de ciertos elementos iconográficos tiene como objetivo la ilustración de mensajes de alto contenido simbólico, ya sea eventos y situaciones mitológicas, o eventos históricos cuyo contexto se aproxima al de dichos eventos mitológicos. Dado que ciertos elementos iconográficos poseen de forma inherente una carga simbólica polisémica, en ocasiones el pintor o escultor maya empleaba la escritura con el fin de denotar de forma unívoca el elemento que deseaba representar. Dado el carácter altamente figurativo de la escritura maya, ésta se integraba visualmente a los elementos iconográficos de la obra, manteniendo el conjunto una uniformidad que las formas escritas no rompen. Un ejemplo de este uso de la escritura con el fin de denotar de forma clara el elemento iconográfico que está siendo representado lo podemos encontrar en las bandas celestes adornadas con cabezas de ave, objeto de estudio del presente artículo. Dichas aves pueden ser de dos tipos, una que posee una mano por mandíbula y otra que porta un espejo en la frente. Diferentes análisis nos demuestran que dichas aves operan como el logograma CHAN, "cielo", para indicar de manera más clara y univoca a la banda a la que acompañan y adornan como elemento celestial. [Palabras clave: banda celeste, ave con mandíbula de mano, ave con espejo en la frente, logograma CHAN, denotación iconográfica.]
\end{abstract}

L'oiseau comme « image » du ciel: la présence de l'oiseau chan dans les bandes célestes mayas. Dans la tradition plastique maya, le recours à certains éléments iconographiques a pour but d'illustrer des messages à fort contenu symbolique, qu'il s'agisse d'événements ou de situations mythologiques ou d'épisodes historiques dont le contenu rappelle des situations mythologiques. Compte tenu du fait que certaines images possédaient per se une charge symbolique à sens multiples, il arrivait qu'un peintre ou un sculpteur eût recours à l'écriture pour désigner de façon non équivoque ce qu'il voulait représenter. En raison du caractère hautement figuratif de l'écriture maya, un glyphe peut parfaitement s'intégrer aux éléments iconographiques d'une œuvre plastique, l'ensemble présentant une uniformité

* R. Valencia Rivera: Investigador independiente [rogelio.valencia.rivera@gmail.com]; D. Salazar Lama: Doctorado en Estudios Mesoamericanos, UNAM, México [danielsalazarlama@gmail.com].

Journal de la Société des américanistes, 2017, 103-2, p. 9-45. C Société des américanistes. 
que l'élément d'écriture ne rompt pas. Un exemple de l'usage de l'écriture pour connoter clairement un élément iconographique peut être trouvé dans les bandes célestes où apparaissent des têtes d'oiseaux, ce qui est l'objet de la présente étude. Ces oiseaux peuvent être de deux types: les uns présentent une main en lieu et place de la mandibule, les autres ont un miroir sur le front. Plusieurs analyses montrent que ces oiseaux renvoient au logogramme $\mathbf{C H A N}$, « ciel », de manière à indiquer sans équivoque que les bandes où ils apparaissent sont célestes. [Mots-clés : bande céleste, oiseau avec main-mandibule, oiseau avec miroir sur le front, logogramme CHAN, caractérisation de l'image.]

The bird as "image" of the sky: the presence of the chan bird in the Mayan celestial bands. In Mayan pictorial tradition, the use of certain iconographic elements serves to transmit messages with a high symbolic content, whether these messages refer to mythological narratives, or illustrate historical events that approximate mythical ones. Due to the fact that some iconographic elements possess an inherent multivalued symbolic content (i.e. they are polysemic), sometimes the Maya painters or sculptors used writing to denote univocally the element they tried to represent. Because of the highly figurative character of Maya glyphs, they integrated gracefully with the different iconographic elements, giving the whole piece a uniformity that was not broken by the introduction of writing. We can find one example of this with the denotation of iconography in Sky Bands adorned with bird's heads, the subject of the present paper. These bird's heads could be of two types, one with a hand as the inferior mandible and the other wearing a mirror on its forehead. The analysis provided in the paper demonstrates that both were used as the logogram CHAN, "sky", to indicate in a very clear and unambiguous way that the bands they were represented with refer to a celestial environment. [Key words: sky band, bird with a hand in the mandible, bird with a mirror on the forehead, CHAN logogram, iconographic denotation.]

\section{Elementos de escritura integrados en las imágenes. Relaciones contextuales y complementarias}

En Mesoamérica la integración de elementos de escritura en las imágenes es una práctica común. Acaso los primeros ejemplos se encuentran en las lápidas conocidas como "Los Danzantes” en Monte Albán, Oaxaca (Figura 1a), siendo las más tempranas las que se ubican en el Edificio L-Sub, alrededor del 400 a.C. (Urcid y Joyce 2014, p. 151-152). Algunos de estos monumentos presentan jeroglifos sobre el cuerpo de cautivos mutilados; sin duda se trata de elementos que refieren a los personajes representados, ya sean títulos o nombres personales -algunos de ellos calendáricos (Houston 2004, p. 295-296). Si los elementos gráficos mencionados como jeroglifos, efectivamente se corresponden con los nombres o los títulos de cada personaje, estos deberían ser lexemas, es decir, expresar palabras, y no debemos observarlos como motivos iconográficos. 
Otros posibles ejemplos más tempranos de este uso de la escritura son las cabezas colosales olmecas de San Lorenzo, Veracruz (Figura 1b), muchas de las cuales se pueden fechar para el lapso 1150-900 a.C. Algunas de estas cabezas incluyen elementos en el tocado, en todos los casos diferentes. Se ha sugerido que se trata de los primeros ejemplos de la integración de elementos de escritura en la imagen individualizada de gobernantes tempranos (Diehl y Coe 1995, p. 23; Houston 2004, p. 288-289). Sin embargo, de acuerdo con Houston (2004, p. 289), no existe la suficiente evidencia para considerarlos como puramente nominales. Tal vez se trate de emblemas o conjuntos de elementos que conllevan un significado, pero que no registran claramente palabras ${ }^{1}$.

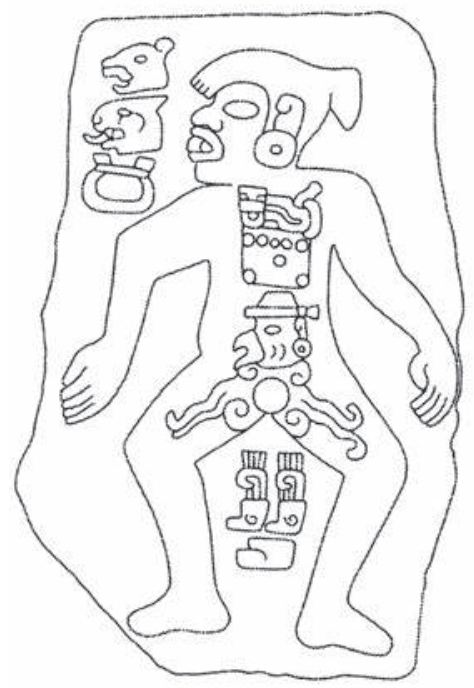

a

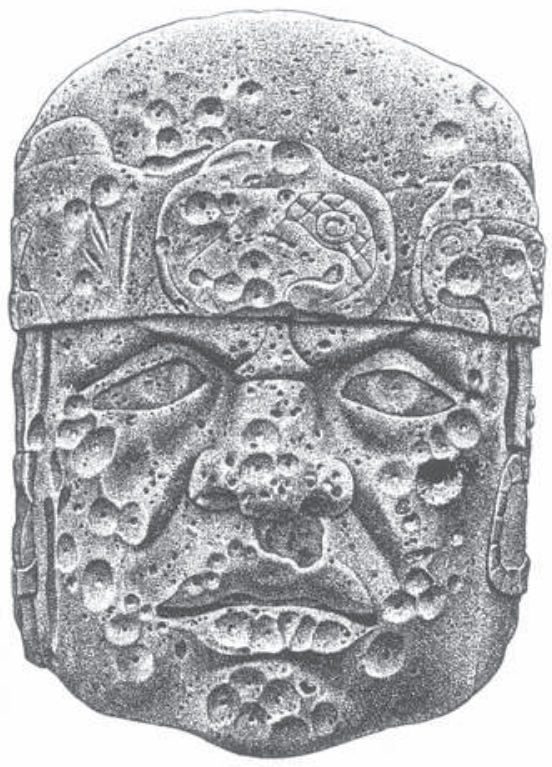

$\mathrm{b}$

Fig. 1 - Ejemplos mesoamericanos de integración de elementos de escritura en la imagen: a. Lápida D-55 del Edificio L-Sub de Monte Albán. Dibujo de Elbis D. Covarrubias, tomado de Urcid y Joyce (2014); b. Monumento 2 de San Lorenzo. Dibujo tomado de Houston (2004).

Al igual que Houston (2004, p. 290), consideramos que el elemento que aporta significados (el nombre) se incorpora al contexto del elemento que los recibe

1. En ese caso, los elementos en los tocados funcionarían como otros ejemplos de emblemas olmecas utilizados en la representación de localidades. Para una discusión más amplia, consultar el trabajo de Stephen Houston ya citado (Houston 2004). 
(el personaje). Dicha integración de elementos de escritura en las imágenes es designada por otros investigadores como "asimilación pictórica" (Stone y Zender 2011, p. 24-25).

\section{Ejemplos de "asimilación pictórica" en el área maya}

En las obras plásticas mayas del Periodo clásico es frecuente encontrar este tipo de integración o asimilación pictórica bajo distintos aspectos y cumpliendo diversas funciones (Salazar Lama y Valencia Rivera 2017). En los mascarones witz "montaña", por ejemplo, muchas veces se pueden encontrar elementos de escritura en el entrecejo (por ejemplo mascarones witz en el friso de Balamkú, Campeche; Figura 2a y b), sobre la cabeza zoomorfa (por ejemplo witz pintados en la Tumba 2 de Río Azul; Figura 2c) o dentro de los ojos (por ejemplo witz en el tablero del Templo de la Cruz Foliada de Palenque; Figura 2d). En estos casos los jeroglifos expresan los nombres de las montañas como localidades determinadas; es decir, funcionan como topónimos que las particularizan (Salazar Lama 2014, p. 41-42). Otro ejemplo claro de la integración de elementos de escritura en la imagen de un lugar es el tablero del Templo XIV de Palenque (Figura 2e). La imagen muestra una compleja banda acuática con rizos de agua o conchas, hileras de puntos, bandas horizontales y signos de la sílaba le, que aquí funcionan como alusión a plantas acuáticas (Kettunen y Helmke 2013, p. 28); se trata de una representación un tanto general de un ambiente acuático. Sin embargo, el jeroglifo central puede leerse como $t i$ ' $k$ 'ahk' naahb, “orilla del mar", definiendo con esto que no se trata de un lugar acuático cualquiera, sino un espacio específico ${ }^{2}$.

En los ejemplos antes descritos, el elemento jeroglífico se suma a la representación gráfica de un lugar -la cual incluye todos los atributos y las características propias del espacio mediante motivos iconográficos de contenido simbólico-, funcionando como una referencia que define de manera unívoca lo que se representa en la imagen ${ }^{3}$.

2. Kettunen y Helmke (2013, p. 28-29, fig. 10) sugieren que en el tablero del Templo XIV, dentro de los signos jeroglíficos que componen el nombre $k$ 'ahk'-naahb, "mar", el signo TI', que precede a los signos K'AK' y NAB, funciona como partícula locativa para lugar, similar a "en". Nosotros consideramos que en este caso el signo TI' se refiere a "boca", u "orilla", integrándose al compuesto jeroglífico que designa al lugar como una partícula que ayuda a definirlo más precisamente. La preposición "en" se indica, dentro de estos contextos, de manera iconográfica mediante la localización del texto dentro de la imagen.

3. En otros casos, la referencia gráfica a un lugar está conformada únicamente por elementos jeroglíficos que se integran a las escenas, funcionando como topónimos. Claros ejemplos son la Estela 4 de Yaxchilán, con el glifo emblema $\mathrm{Pa}$ ' Chan, "cielo partido", configurado a partir de la variante de cabeza de CHAN y una hendidura sobre su frente; la Estela 3 de Yaxhá, y la Estela 7 de Ceibal (ver Stuart y Houston 1994, p. 57-63). 

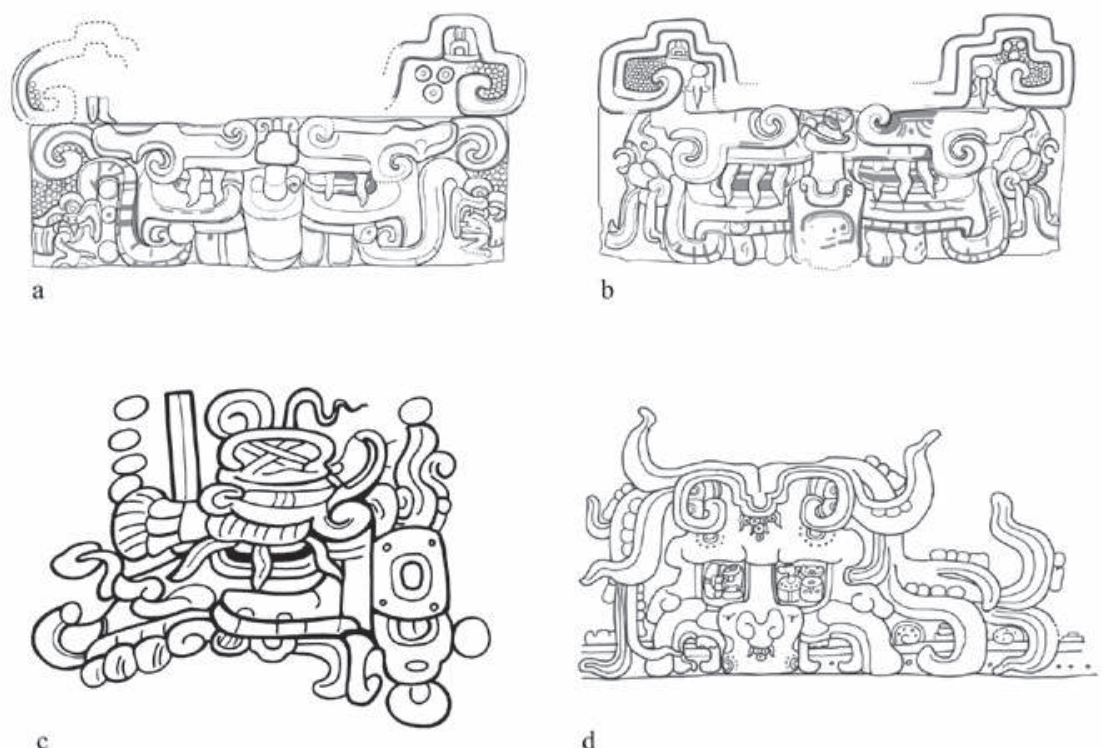

c

d

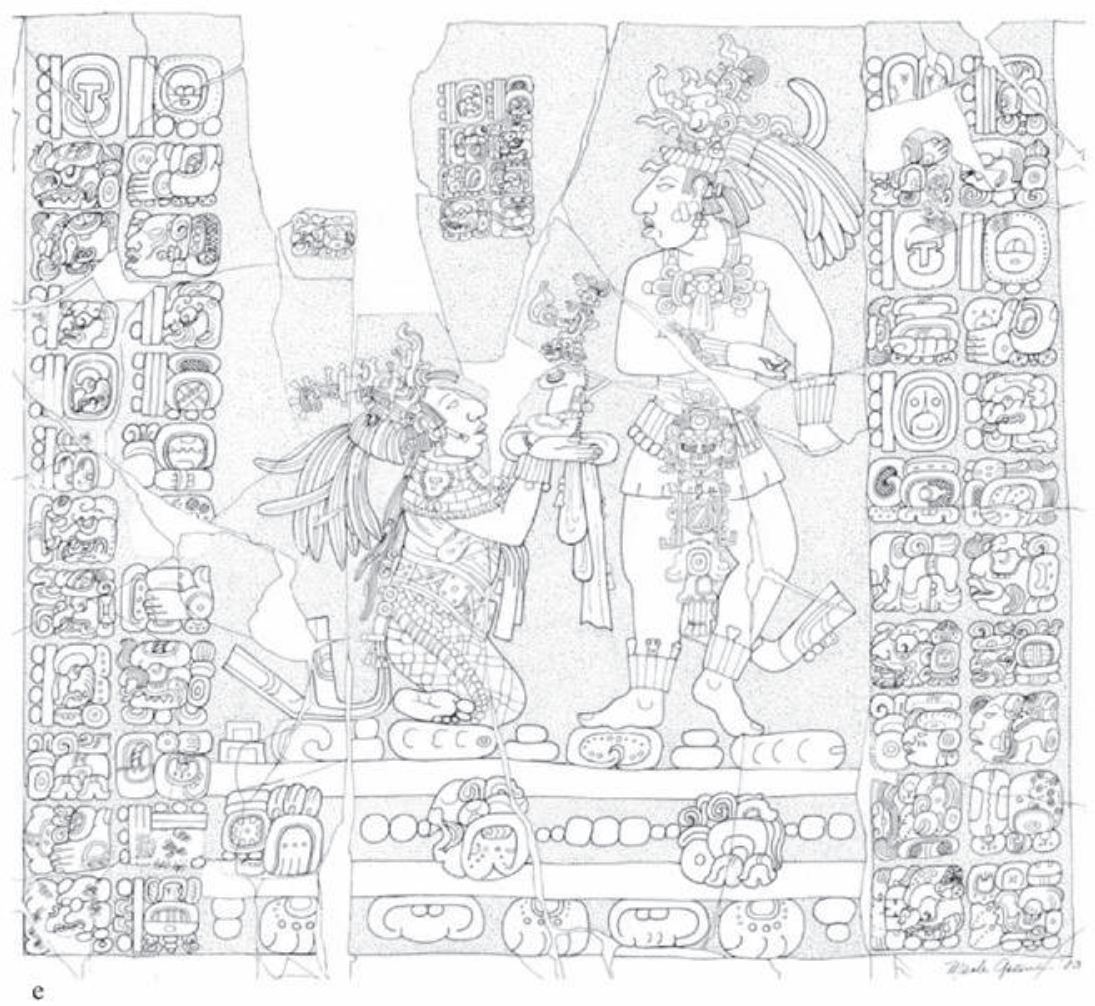

Fig. 2 - Representaciones gráficas de localidades con elementos jeroglíficos: a. Mascarón witz n. ${ }^{\circ} 2$ del friso de Balamkú. Dibujo de Daniel Salazar;

b. Mascarón witz n. ${ }^{\circ} 3$ del friso de Balamkú. Dibujo de Daniel Salazar; c. Witz en muro este de la Tumba 2 de Río Azul. Dibujo de Daniel Salazar, basado en dibujo previo presentado por Acuña (2007); d. Witz en el tablero del Templo de la Cruz Foliada de Palenque. Dibujo de Linda Schele, en www.famsi.org; e. Tablero del Templo XIV de Palenque. Dibujo de Merle Greene Robertson. 
Otro tipo de asimilación pictórica en la plástica maya son los llamados tocados nominales, considerados como una herencia de la tradición escultórica olmeca, y presentes en toda Mesoamérica (Kelley 1982). Uno de los ejemplos más tempranos del área maya es el Monumento 65 de Kaminaljuyú (Figura 3) -probablemente perteneciente al siglo II d.C. (Henderson 2013, p. 212, nota 31) donde se muestra a tres gobernantes sentados en tronos y portando sobre sus cabezas distintos elementos jeroglíficos en sus tocados, lo que ha sido interpretado como antropónimos individualizados (Parsons 1986, p. 58; Kaplan 2000; Henderson 2013, p. 212). Uno de los ejemplos más representativos de esta práctica, sin embargo, es la Estela 31 de Tikal (véase Stone y Zender 2011, fig. 8, p. 24-25). En ella, el personaje central de la imagen, el gobernante Siyaj Chan K'awiil, "K'awiil nace en el cielo", porta su antropónimo sobre la cabeza, configurado a partir del logograma CHAN" "cielo", hendido, del cual emerge la figura del dios $K$ 'awiil con los brazos flexionados (postura que remite al jeroglifo sih, "nacer"). Houston y Stuart (1998, p. 83) sugieren que a través de este tipo de recursos emblemáticos se presentan de forma tangible y concreta ciertos aspectos personales y referencias a la identidad de los personajes; como una manera de individualizarlos.

Esta idea cobra especial sentido si consideramos que la imagen de la figura real en el arte maya, sobre todo durante el Clásico temprano, no tiene una intención retratista, y los gobernantes y antepasados se muestran con facciones y características corporales estandarizadas y convencionales, a veces incluso esquemáticas. En estos casos, el tocado nominal funciona perfectamente como un elemento que introduce un rasgo de especificidad en la imagen ${ }^{5}$.

Por último, la integración de elementos jeroglíficos en la imagen puede también expresar fechas, cantidades, materiales o contenidos. Tal es el caso de sacos marcados con las grafías bu'ul, "frijol", o kakaw, "cacao", que claramente expresan el contenido invisible de los bultos; o las pelotas de hule utilizadas

4. La transliteración de textos escritos con signos jeroglíficos mayas se realiza usando negritas, los fonogramas en minúsculas y los logogramas en mayúsculas, separados por guiones y los signos reconstruidos se indican entre corchetes. Asimismo, para su transcripción, los textos se escriben en cursivas y en minúscula, salvo nombres propios que se escriben con mayúscula inicial (Lacadena et al. 2010). Para hablar de un signo en particular, se puede emplear tanto su transliteración, como su transcripción.

5. En la plástica maya, el retrato -al menos el retrato como se concibió en el Occidente- se desarrolla hasta el Clásico tardío en muy pocos sitios y solamente en torno a ciertos personajes. Sin duda los mejores ejemplos son el conjunto de retratos de K'inich Janahb' Pakal y de K'ihnich Kan Bahlam en Palenque, las imágenes de Yuhkno'm Ch'en, gobernante de Calakmul, y de Ukit Kan Lek Tok', gobernante de Ek' Balam, en la tapa de bóveda n. ${ }^{\circ} 15$, donde se muestra con la deformación en la mejilla provocada por una enfermedad dental (Lacadena 2003). 
El ave como cielo

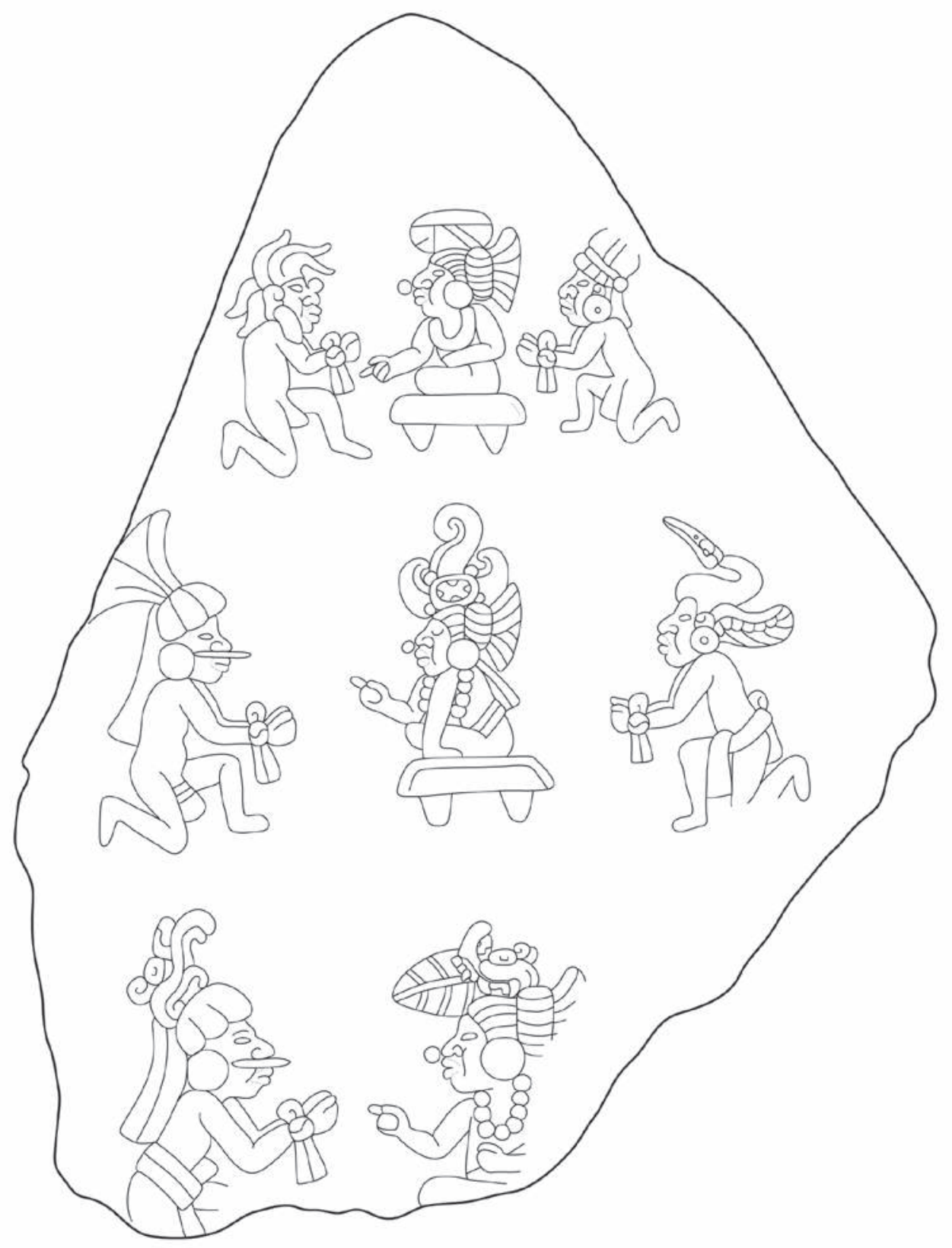

Fig. 3 - Escultura 65 de Kaminaljuyú. Dibujo de Lucia Henderson, tomado de Henderson (2013). 
en el juego de pelota, en las que se indica sus medidas específicas, baluun-nahb, "nueve palmas" (Zender 2004; Stone y Zender 2011, p. 26) ${ }^{6}$.

\section{Bandas celestes y aves en la imaginería maya}

Nuestra hipótesis es que el objeto de estudio del presente trabajo, las bandas celestes del Clásico temprano (200/250-600 d.C.) y tardío (600-900 d.C.) a las que se añaden cabezas de ave, pueden ser un ejemplo más de la integración e interacción de elementos de escritura en las imágenes.

Para lograr una interpretación integral sobre dichos casos, el análisis será efectuado en dos etapas: la primera avocada a examinar la relación formal, espacial y compositiva de ambos componentes, así como su comportamiento a lo largo de los períodos considerados; la segunda, en la que se analizará a las aves involucradas desde un enfoque epigráfico.

Al abordar nuestros casos de estudio, encontramos que un posible primer ejemplo de la integración de cabezas de ave en bandas celestes incipientes se observa fuera del área maya y probablemente pertenece a los finales del Preclásico tardío ( ca siglo I o II d.C. Barthel y Von Winning 1991): se trata de la estela de El Mesón, Veracruz (Figura 4), sitio ubicado muy cerca de la región de Los Tuxtlas, zona cultural con la que los mayas mantuvieron contacto durante distintas fases de su historia (Valencia Rivera 2017a). A pesar de que por el momento no podemos constatar que dichas aves sean elementos de escritura con valor fonético, sí consideramos que esta estela podría ser un antecedente de las bandas celestes con aves del Clásico maya.

Ya durante el Clásico, las bandas celestes constituyen motivos iconográficos bastante frecuentes en la plástica maya. Varios investigadores (Quirarte 1974; Taube 1995; Carlson y Landis 2000; Taube et al. 2010) sugieren que modificaron sustancialmente algunos de sus rasgos diagnósticos con el paso del Preclásico tardío al Clásico. Durante el lapso 200/250-900 d.C. -temporalidad en la que nos centraremos en este trabajo- las bandas celestes están configuradas a partir de varios componentes más o menos estables (Figura 5a): una serie de cartuchos rectangulares con signos estelares, entre los que encontramos K'IN, "sol"; AK'AB, "oscuridad, noche"; UH, "luna"; EK', "estrella", la variante de cabeza del signo de brillo o hacha de jade, y el jeroglifo CHAN,

6. Hemos decidido excluir de este estudio los llamados "calificadores de propiedades". Según Stone y Zender (2011, p. 13-15), son elementos abstraídos de logogramas específicos y utilizados en las imágenes para referir el material de los objetos, su color o, más conceptualmente, la naturaleza de ciertos seres con respecto a los distintos ámbitos del cosmos (por ej. las marcas de TUN, "piedra", en los dientes de los mascarones witz; marcas TE', "madera/árbol", en las canoas y en los troncos de los árboles). La razón de dicha exclusión es que estos elementos no conllevan una lectura dentro del contexto en el que se integran. 
El ave como cielo

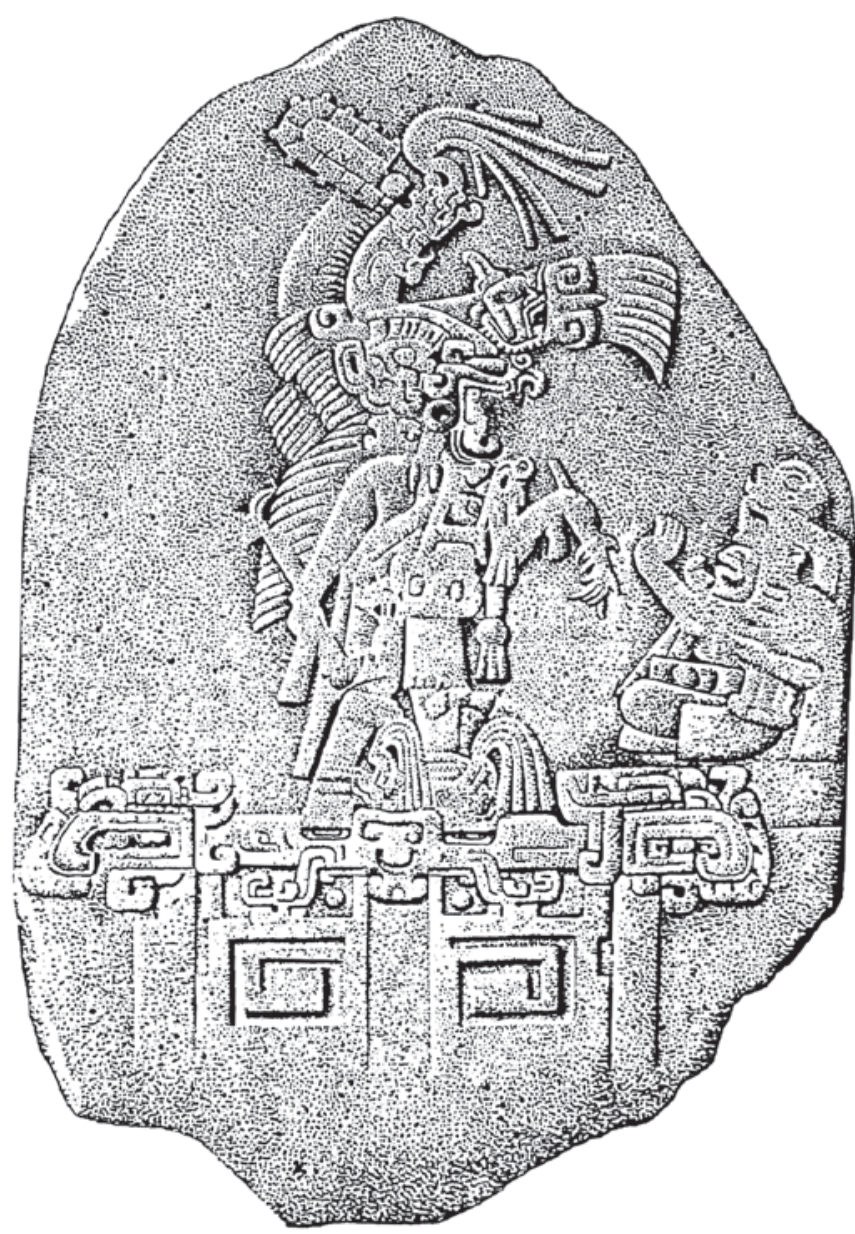

Fig. 4 - Estela de El Mesón. Dibujo de Covarrubias tomado de Barthel y Von Winning (1991, fig. 4).

"cielo", en sus distintas versiones abstractas y bandas diagonales cruzadas, todos dispuestos dentro de una franja horizontal acompañada a veces por un reborde delgado con volutas y signos trilobulados. En algunas ocasiones los extremos de la franja horizontal se encuentran rematados con grandes cabezas colgantes de serpientes u otras criaturas celestiales ${ }^{7}$. Entre las criaturas más frecuentes se

7. Existen pocos casos de bandas celestes del Clásico que incluyen elementos iconográficos arcaicos, como líneas diagonales o motivos en forma de corchetes -rasgos característicos de las bandas celestes de Izapa (por ej. estelas 1, 2, 4, 8, 10, 11 y 21) que se pueden ver en el segundo mascarón, lado sur, del edificio A1 de Kohunlich (ver Salazar Lama 2015, 
hallan la cabeza de un cocodrilo con rasgos de venado y estrellas en el rostro y el llamado "monstruo cuadripartito" o "tazón $k$ 'in" personificado ${ }^{8}$-ambos conformando junto con la banda celeste el cuerpo del "Cocodrilo-Venado Estelar" (Figura 5c; consultar Stuart 2005, p. 167-168; Martin 2015; Velásquez García 2006)-; serpientes estilizadas con tres extensiones y un motivo ovalado en el extremo del hocico (por ejemplo banda celeste en el mascarón de Yehnal; Figura 7c), y serpientes con el hocico cuadrado y volteado hacia arriba (por ejemplo cabeza norte [izquierda] de la banda celeste del tablero de Margarita; Figura $7 \mathrm{~d})^{9}$. Esta conjunción de elementos se desarrolla ampliamente a lo largo del Clásico; sin embargo, hemos detectado que aparece por primera vez en el Altar 12 de Tak'alik Ab'aj (Figura 5b), fechado para el Preclásico tardío.

La forma general de las bandas celestes puede adquirir el aspecto de un marco cerrado por sus cuatro lados (por ejemplo lápida del Templo de las Inscripciones de Palenque); un marco incompleto, cerrado únicamente por la parte superior y los lados (por ejemplo relieve de estuco de la Casa E del palacio de Palenque [Figura 5c]; Estelas 4 y 10 de Yaxchilán), o solamente como una banda horizontal sencilla (por ejemplo friso del Edificio A-Sub del Grupo II de Holmul; banda celeste sobre un muro en la Pequeña Acrópolis de Dzibanché).

Consideramos que, al igual que otros elementos iconográficos como las bandas acuáticas y terrestres, los mascarones witz, "montaña", y las representaciones de cuevas, las bandas celestes en cualquiera de sus formas funcionan como marcadores espaciales; es decir, definen el entorno en el que se encuentran ciertos personajes y donde se desarrollan algunas de sus acciones ${ }^{10}$.

Como motivos iconográficos presentes en la plástica maya a lo largo de muchos siglos, las bandas celestes experimentan variantes formales locales y tendencias regionales dignas de analizar. En este trabajo nos interesan particularmente las bandas celestes que incluyen cabezas de ave en las esquinas o en ambos extremos.

fig. 20d)-, y grecas escalonadas, como las que aparecen en las bandas celestes en el Templo del Sol Nocturno en El Zotz (Taube y Houston 2015, fig. 5.3 y 5.6).

8. Los términos de "monstruo cuadripartito", "insignia cuadripartita", "tazón $k$ 'in personificado" son utilizados en la literatura especializada para designar a un mismo motivo iconográfico conformado por una espina de mantarraya, una concha seccionada y un elemento foliado sobre un tazón marcado con el signo k'in, que en algunos casos se muestra con un cráneo añadido a la parte posterior de la criatura (consultar Schele y Freidel 2000, p. 540; Stuart 2010, p. 166-168).

9. Esta particular serpiente es generalmente llamada "monstruo Zip" en la literatura especializada (consultar Carlson y Landis 2000, p. 232-233).

10. En el caso particular de las bandas celestes integradas al cuerpo del Cocodrilo-Venado Estelar, coincidimos con Stuart (2010, p. 70-77), con Velásquez García (2006) y con García Barrios (2015, p. 16-18, 41-42) al considerarlas como representaciones de espacios cosmológicos que además aluden a episodios míticos concretos. 
El ave como cielo
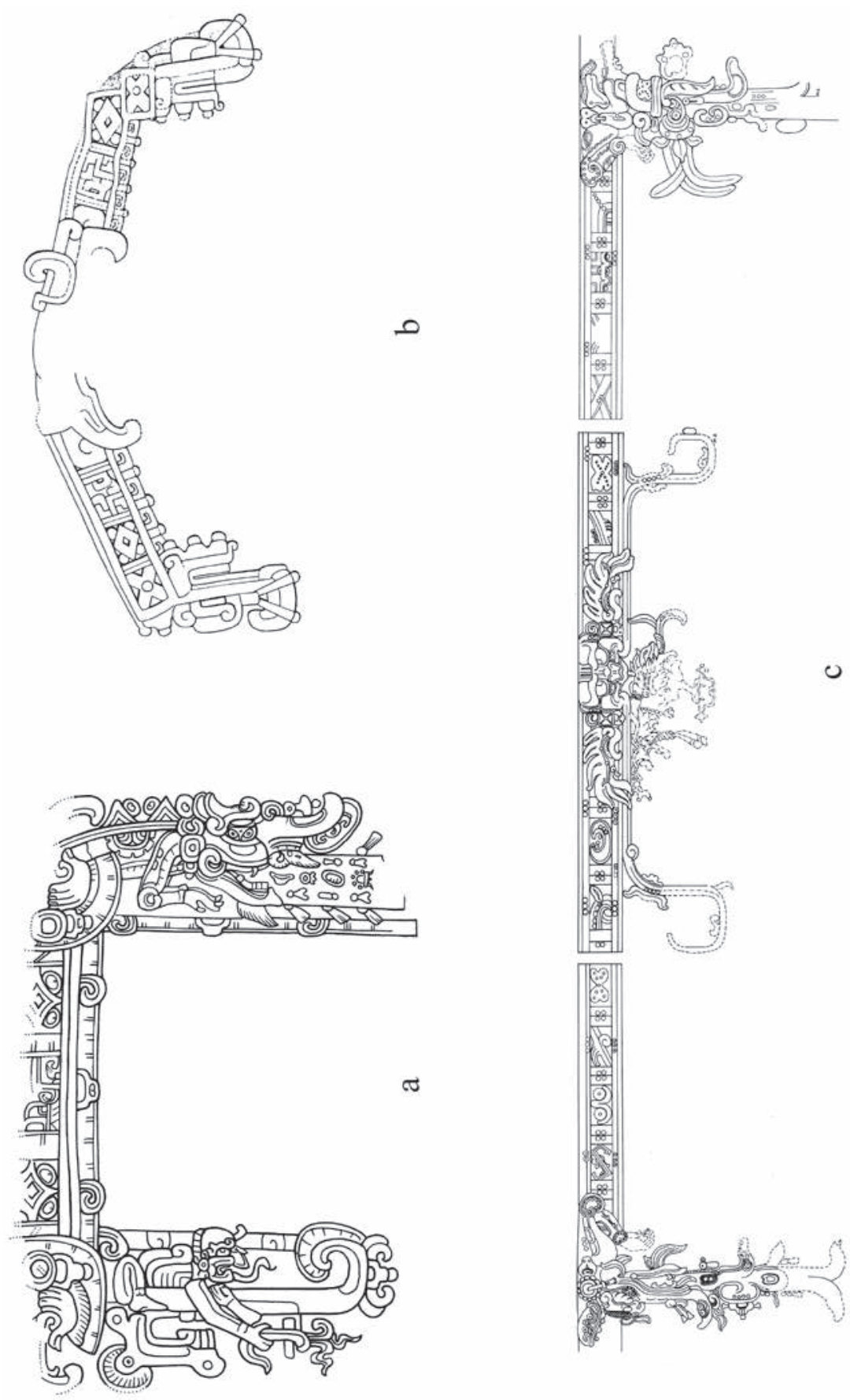

을 苑

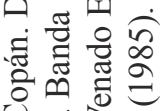
$0 \div>$ ज्ञ을 흉ㅎㅇ t 응 궁

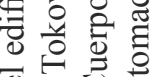
ब ㅇํㅇㅇㅛ 产氙 궁 0 षृ 0

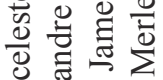
웡 击 $\frac{0}{8} \stackrel{\circ}{\exists}$ ๑ 응 $\therefore$ 用 نे बํํㄹ

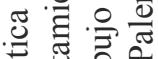
兽票产

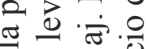
वै 这峦 造 क 응 䂧 宽 잉 的敋 宔。 
Al respecto, hemos detectado que existen dos tipos de aves: una con la mandíbula en forma de mano y otra con un espejo en la frente. En primer lugar, el ave con la mandíbula de mano, cuyas características diagnósticas se señalan en la Figura 6, se ubica de forma exclusiva en las esquinas de bandas celestes que enmarcan las escenas por la parte superior y los lados (Figura 7); debajo de ellas penden cabezas de serpientes u otras criaturas celestiales en posición descendente, y solamente en un caso, el relieve del Edificio Macizo en la Acrópolis de Copán (Figura 7b), se presenta una extensión de la franja horizontal superior puesta de manera vertical, aunque el Cocodrilo-Venado Estelar desciende inmediatamente por detrás de la cabeza del ave ${ }^{11}$.

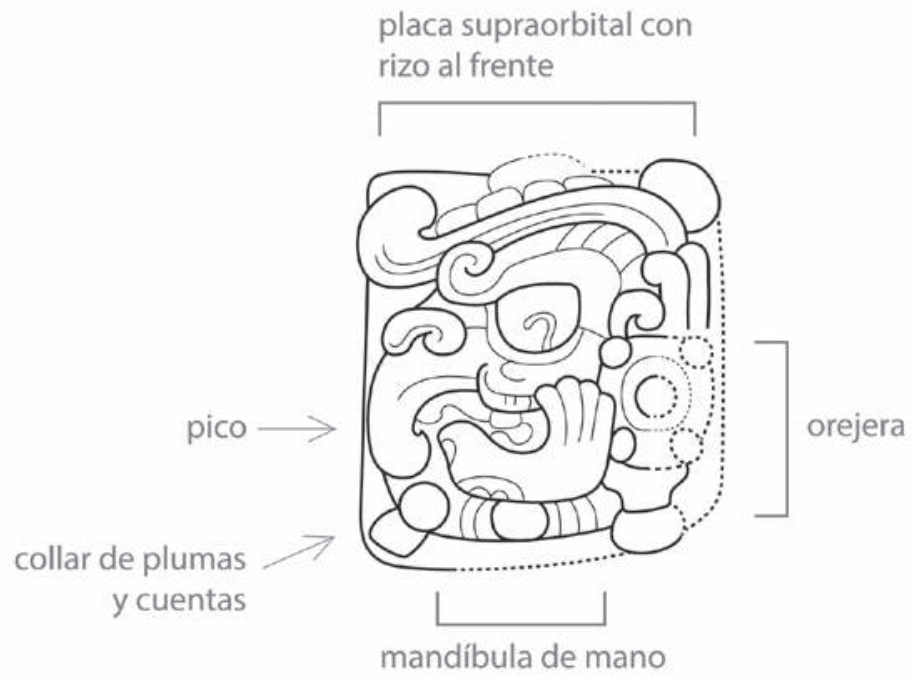

Fig. 6 - Rasgos diagnósticos del ave con mandíbula de mano.

Dibujo de Daniel Salazar, basado en dibujo previo de Heather Hurst, en Saturno, Hurst y Rossi (2012).

Es difícil identificar la cabeza de esta ave con un referente natural. Su pico ancho, curvo y redondeado en la punta, y la colocación de la nariz en el arranque de dicho pico son rasgos que recuerdan a las características de la Deidad Ave Principal (ver Bardawil 1976, p. 198), mientras que su ojo, que presenta muchas variantes entre todos los ejemplos, no es identificable en aves del

11. La criatura mencionada se encuentra en posición descendente con los brazos y las piernas cruzadas y con marcas de estrella en ambas extremidades y a la altura del rostro. Este ser se encuentra flanqueado por extensiones de la banda celeste en posición vertical. Para una discusión más detallada y actualizada del Cocodrilo-Venado Estelar consultar Stuart (2010); Velásquez García (2006) y García Barrios (2015). 
a

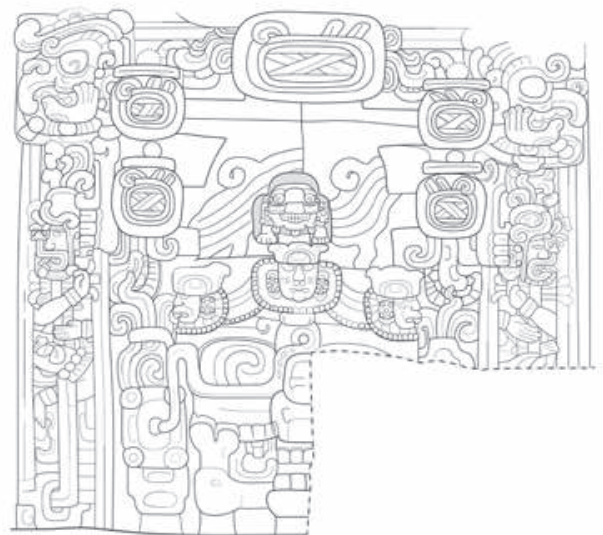

c

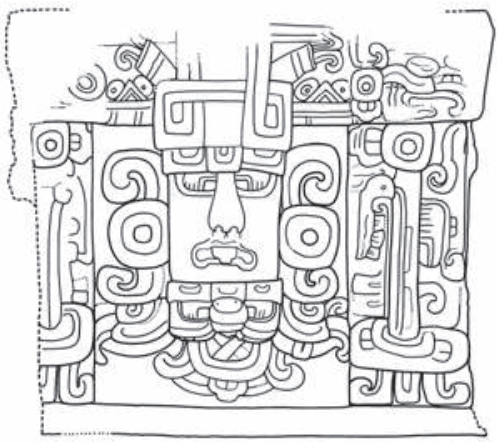

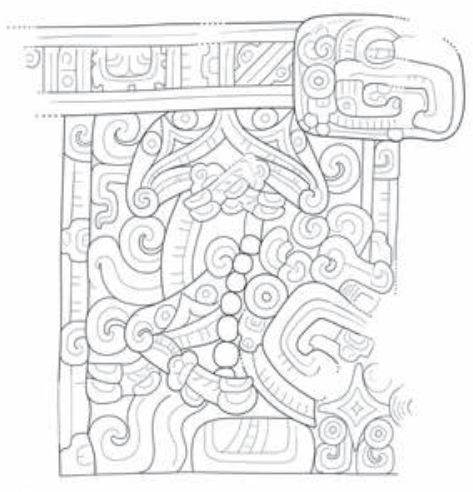

b

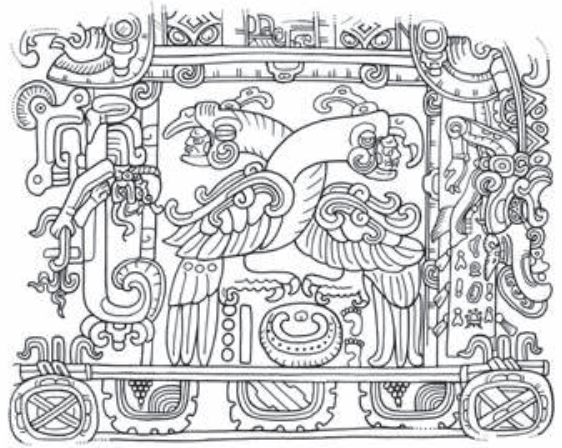

Fig. 7 - Bandas celestes con ave de mandíbula de mano:

a. Mascarón de la plataforma Bayal, Acrópolis Los Árboles de Xultún. Dibujo de Daniel

Salazar, basado en dibujo previo de Heather Hurst, en Saturno, Hurst y Rossi (2012);

b. Relieve de edificio Macizo, Acrópolis de Copán. Dibujo de Daniel Salazar, basado en levantamiento 3D en Fash et al. (2014); c. Mascarón del edificio Yehnal, Acrópolis de Copán. Dibujo de Daniel Salazar, basado en levantamiento 3D de Alexandre Tokovinine, en Tokovinine (2013); d. Tablero del edificio Margarita, Acrópolis de Copán. Dibujo de Daniel Salazar, basado en levantamiento 3D de Alexandre Tokovinine, en Tokovinine (2013).

mundo natural ${ }^{12}$. El rizo sobre la frente, por su parte, es cercano en cuanto a su forma al rizo de los quetzales en la imaginería maya, aunque presenta ciertas diferencias. En resumen, creemos que se trata de un ave de rasgos híbridos o mezclados que no puede adjudicarse a una especie en particular, únicamente

12. En ningún caso las aves integradas en las bandas celestes del Clásico tienen ojos con pupilas cuadradas y esquinadas, signos yax sobre la cabeza u otros rasgos exclusivos de la Deidad Ave Principal, por lo que aclaramos que no consideramos que se traten de avatares o aspectos de dicha deidad aviar. 
identificable por su enorme pico, su rizo en la frente y, desde luego, por su peculiar mandíbula.

Temporalmente, la presencia de esta ave en las bandas celestes se restringe casi exclusivamente al Clásico temprano (200/250-600 d.C.). Hasta el momento, el primer caso registrado proviene de los mascarones de la plataforma Bayal en la Acrópolis Los Árboles de Xultún (Figura 7a), fechados para la fase Tzakol 1 (250-300 d.C.) (Saturno, Hurst y Rossi 2012, p. 561). Asimismo, es interesante notar que la mayoría de los ejemplos donde aparece ha sido reportada en Copán, en los programas escultóricos de las fachadas de los edificios Yehnal, Macizo y Margarita (Figuras $7 b-d)^{13}$.

Tomando en cuenta que la cabeza del ave con mandíbula de mano tiene por lo general un collar que abarca la parte inferior y lateral trasera, marcado con líneas que pueden indicar plumas (ver Figura 7a, b y d), consideramos viable sugerir que la banda celeste de estuco del talud de la Plataforma 2 de Toniná, perteneciente al Clásico tardío -600-900 d.C. (Figura 8a), pudo estar delimitada en su extremo poniente por una de estas aves, de la cual solamente quedan restos de este posible collar ${ }^{14}$.

Por su parte, el relieve de estuco del cuarto cuerpo del Templo I de Dzibanché, fechado entre el 300 y el 450 d.C. (Campaña Valenzuela 1995, p. 30-31), muestra una cabeza con rasgos similares a los del ave con mandíbula de mano (Figura 8b); sobre todo la placa supra orbital con un rizo al frente, el punto que define partes del cuerpo colocado en la esquina de la mandíbula ${ }^{15}$, y el ojo con párpado que se ve en los ejemplares de Yehnal y Macizo. En cuanto a la mandíbula de mano, debemos aclarar que la parte inferior de la cabeza del ave se encuentra sumamente deteriorada, y sólo bajo un estudio detallado de los fragmentos conservados y del registro fotográfico hecho por la Arqueóloga Luz Evelia Campaña se pudo reconstruir parcialmente la forma original de la mandíbula, como lo muestra el dibujo de la Figura $8 \mathrm{~b}$. Al igual que los

13. Otro posible caso del Clásico temprano es el mascarón del Edificio N9-56 de Lamanai $-450-550$ d.C. (Figura 8c), con un elemento que recuerda el aspecto del ave en los extremos de una banda celeste horizontal. Sin embargo, las fotografías de las que disponemos y el estado de conservación del estuco actualmente imposibilitan identificar con certeza al ave. Asimismo, existe una piedra tallada de procedencia desconocida fechada tentativamente para el 517 d.C. (consultar Mayer 1989, p. 24; Plates 122 y 123) que contiene una banda celeste en la parte superior de la escena, en cuyo extremo derecho se encuentra la cabeza de un ave. Hemos decidido no integrar este ejemplar a la discusión debido a que en las imágenes presentadas no es posible distinguir los detalles de la cabeza del ave, y no reconocemos si se trata de un caso de mandíbula de mano o si el ave tiene una mandíbula normal.

14. Un collar similar se observa en las cabezas de ave de la estela de El Mesón, por lo que pensamos que pueden tener relación con las aves de las bandas celestes mayas del Clásico.

15. Aunque este elemento no aparece en todos los ejemplos del ave con mandíbula de mano, sí se puede apreciar en el relieve de Macizo (Figura 7b) y en los mascarones del edificio Bayal de Xultún (Figura 7a). 

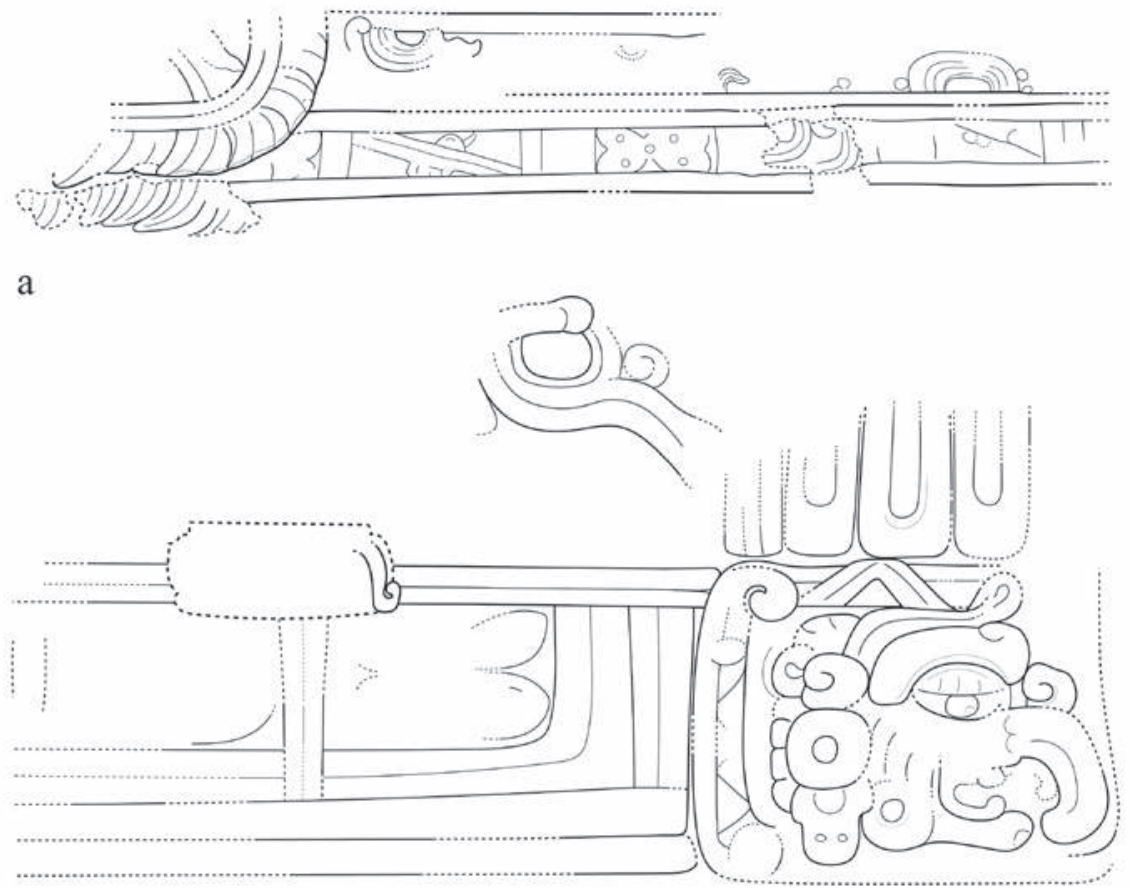

b

c

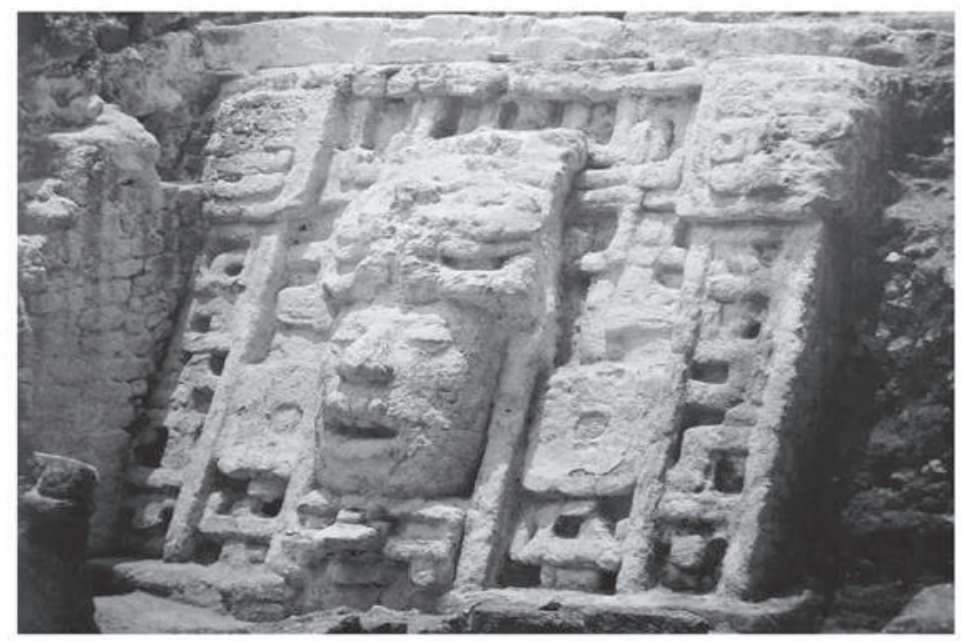

Fig. 8 - a. Relieve de la Plataforma 2 de Toniná. Dibujo de Daniel Salazar; b. Relieve del Templo I de Dzibanché. Dibujo de Daniel Salazar, basado en fotografías del autor y en los registros fotográficos de Luz Evelia Campaña y de Rogelio Valencia; c. Mascarón de edificio N956 de Lamanai. Fotografía tomada de Segovia Pinto (1981). 
ejemplos de Yehnal, Macizo y Margarita, la cabeza del ave en el Templo I de Dzibanché se encuentra en el extremo de una banda celeste ahora perdida casi en su totalidad. El elemento mejor conservado es un cartucho rectangular con el signo $k^{\prime}$ in al centro.

La segunda cabeza de ave que hemos detectado en las bandas celestes es la que tiene un espejo integrado en la frente. Sus rasgos diagnósticos, que se muestran en la Figura 9, difieren considerablemente de los del ave con mandíbula de mano. Esta ave ocupa los extremos de bandas celestes horizontales (por ejemplo bandas celestes en la Estela 32 de Naranjo; Figura 10a) o los extremos inferiores de bandas cuya forma recuerda a una "U" invertida o un marco incompleto (por ejemplo monumento de Moral-Reforma, Tabasco; monumento en la plataforma frontal del Templo del Norte de la Gran Acrópolis de Edzná; Estela I de Quiriguá; Figuras 10b-d); en todos los casos, las cabezas de ave apuntan hacia los lados y en direcciones opuestas.

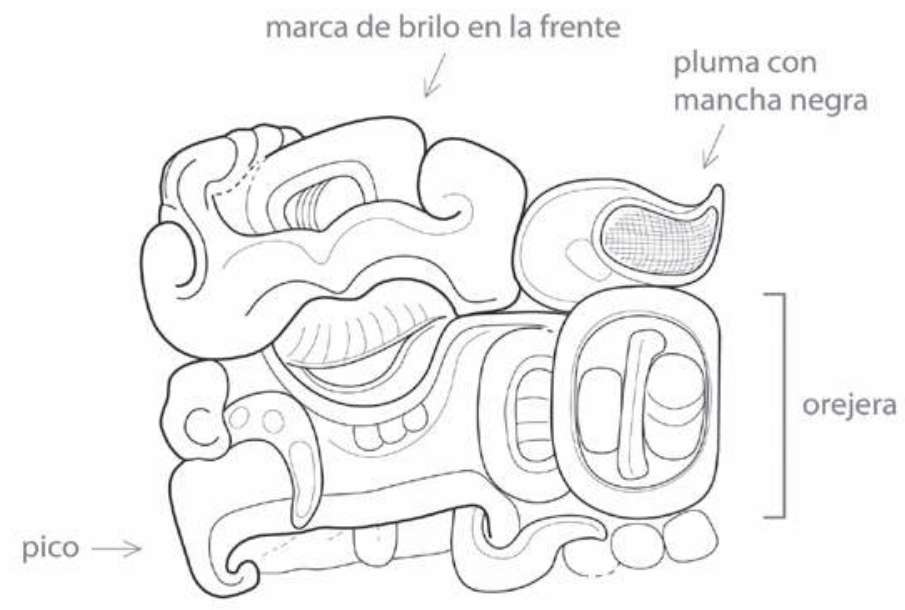

Fig. 9 - Rasgos diagnósticos del ave con espejo en la frente.

Dibujo de Daniel Salazar, basado en fotografías del autor y de Rogelio Valencia.

En la Estela 32 de Naranjo las bandas celestes y las aves se integran a un andamio con una escalera central (similar a muchas estelas tipo nicho de Piedras Negras). Las tres bandas celestes y las aves en sus extremos no se encuentran diferenciadas entre sí por sus elementos componentes o rasgos particulares. En este caso creemos que no se trata de la representación de un espacio cosmológico estratificado, y al igual que lo sugieren Nielsen y Sellner (2015, p. 36) para la "Lápida de los cielos" del centro de México, sugerimos que el conjunto 


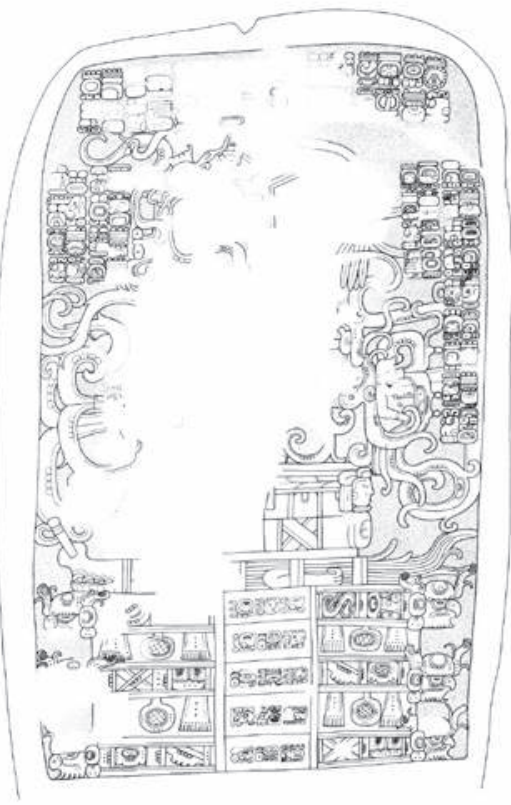

a

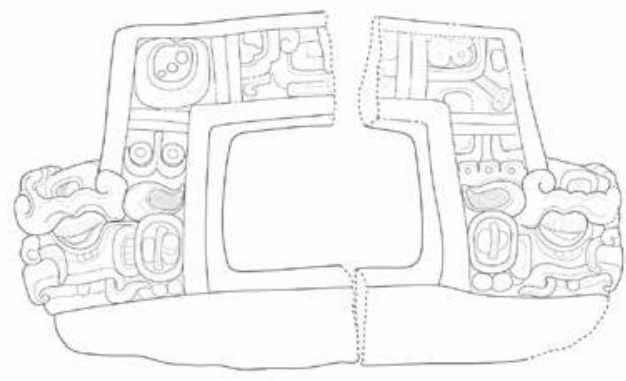

b

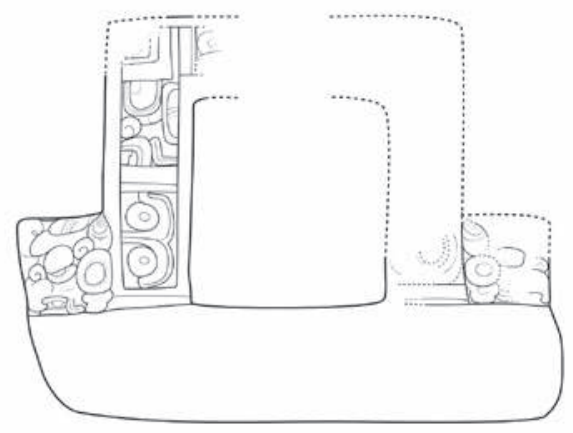

c

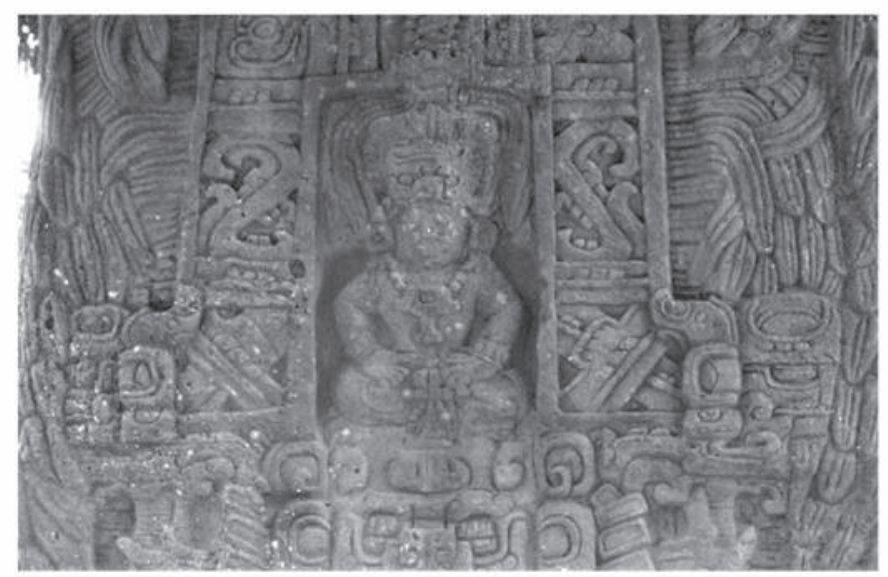

d

Fig. 10 - Bandas celestes con ave de espejo: a. Estela 32 de Naranjo. Dibujo de Linda Schele; b. Escultura de Moral Reforma. Dibujo de Daniel Salazar, basado en fotografías del autor y de Rogelio Valencia; c. Escultura del Templo del Norte de la Gran Acrópolis de Edzná. Dibujo de Daniel Salazar, basado en estudio fotográfico del autor; d. Detalle de la

Estela 1 de Quiriguá. Fotografía de Linda Schele, en www.famsi.org. 
de bandas sobrepuestas puede estar funcionando como la representación de un cielo profundo y en apariencia infinito, no necesariamente dividido en niveles horizontales consecutivos ${ }^{16}$.

Si observamos más detalladamente la estela de El Mesón, notaremos que las cabezas de ave y la banda celeste simplificada también se encuentran en la sección superior de una especie de estructura vertical. ¿Podría tratarse entonces de un ejemplo rudimentario de andamio? Bajo una mirada comparativa es posible sugerir que así es, sobre todo si consideramos que dicha estructura vertical es parecida a las que se observan en las Estelas 6, 11, 14 y 32 de Piedras Negras, y que sobre ella se encuentra una banda celeste terminada en cabezas de ave, semejante al andamio de la Estela 32 de Naranjo.

De igual forma que el ave con mandíbula de mano, esta ave con el espejo en la frente no presenta rasgos que permitan identificarla con una especie de ave particular. Su pico es puntiagudo y corto, como ave de rapiña; en algunos casos (por ejemplo monumento del Templo del Norte de Edzná) tiene una protuberancia que cae sobre uno de los lados del pico, como si se tratara del "moco" o "redecilla" de los pavos. La característica pluma con la punta negra corresponde con las plumas del ave Muwan, que ha sido identificada como un gavilán, pero más comúnmente como un ave de rapiña sobrenatural (Kettunen y Helmke 2014, p. 113).

Tanto el ave con mandíbula de mano, como el ave con el espejo en la frente tienen una posición recurrente dentro de los arreglos compositivos de las bandas celestes, encontrándose invariablemente en los extremos de la franja que contiene los signos estelares. Esta particular ubicación puede definirse como un nicho funcional; es decir, un espacio determinado dentro de una composición que forma parte de los significados del conjunto, vinculado estrechamente con los elementos o motivos que alberga (Salazar Lama 2014, p. 42, 86 -nota 6).

Un nicho funcional se crea al colocar de forma recurrente un motivo con un mismo significado y función en la misma ubicación dentro de la composición. La carga o el contenido de dicho motivo definirá, gracias a esta recurrencia de posición, la función del espacio que ocupa ${ }^{17}$.

Analizando temporalmente la presencia de ambas aves en las bandas celestes, creemos que el ave con espejo en la frente sustituye al ave con mandíbula de

16. Este planteamiento se contrapone a la idea generalizada de varios autores acerca de la creencia mesoamericana de un cielo estructurado en varias capas superpuestas (ver Becquelin 1995; López Austin 1997; Miller y Taube 2011, p. 153-154, entre otros). En ese sentido, coincidimos con Nielsen y Sellner (2015, p. 53-54) en que no existen pruebas contundentes y claras que indiquen este tipo de creencias sobre la arquitectura del cosmos -más allá de los tres estratos básicos-en los tiempos prehispánicos, incluyendo a los mayas del Clásico.

17. Un claro ejemplo de nicho funcional en la imaginería maya es el entrecejo de los mascarones witz, destinado a colocar topónimos que denominan a las montañas (ver Salazar Lama 2014, p. 57); un jeroglifo colocado en dicha posición adquirirá la función de designar el nombre particular de la montaña como localidad. 
mano hacia el 625 d.C. (9.9.10.0.0). Esta sustitución en parte se corresponde con el cambio en la utilización de dichas aves en el sistema de escritura maya (ver más adelante), el cual ocurre alrededor del 613 d.C. (9.9.0.0.0).

Dentro de este panorama de las bandas celestes, un caso interesante es el fragmento de estuco fotografiado por Walter Sellschopp en 1958 en el sitio de Natentsun, Chiapas (Figura 11, ver página siguiente) (Sheseña Hernández y Tovalín Ahumada 2014), que claramente formaba parte de un programa escultórico más amplio, posiblemente de una fachada arquitectónica. Este fragmento, aunque pequeño, muestra un ave con un espejo en la frente y una mandíbula con forma de mano, y debajo del ave, la cabeza colgante de una serpiente de hocico cuadrado con el extremo volteado hacia arriba. Proponemos que, actuando en conjunto, ambas criaturas formaban parte de una banda celeste más completa, cada una ocupando un nicho funcional específico: el ave en el extremo de una franja con signos estelares (ahora perdida), ubicada sobre la esquina de un marco incompleto, y la cabeza de serpiente como límite lateral izquierdo (comparar con bandas celestes de las Figuras 7a y d). De ser así, esta particular ave que presenta tanto el espejo como la mano en la mandíbula sería un eslabón entre las tradiciones escultóricas que utilizan ambas aves de forma independiente y sin traslaparse.

Un último caso, la Estela 1 de Ek' Balam (840 d.C.) (Figura 12), presenta una banda celeste con una cabeza de ave en uno de sus extremos; esta ave no posee los rasgos básicos de las aves antes descritas y su aspecto es un tanto "genérico", incluso esquemático, difícilmente reconocible por falta de características puntuales. Pensamos que, para la época tan tardía de la estela, esta ave posiblemente sea un elemento arcaizante que remite a una tradición desarrollada en las tierras bajas centrales siglos antes, similar a muchos otros motivos encontrados en el arte y la escritura de Ek' Balam (Lacadena 2008). No obstante, su ubicación en un nicho funcional específico y su naturaleza aviar nos indican que se trata de una variante formal local que se integra al complejo iconográfico asociado a las bandas celestes.

Fig. 12 - Estela 1 de Ek' Balam. Dibujo de Alfonso Lacadena, tomado de Lacadena (2003).

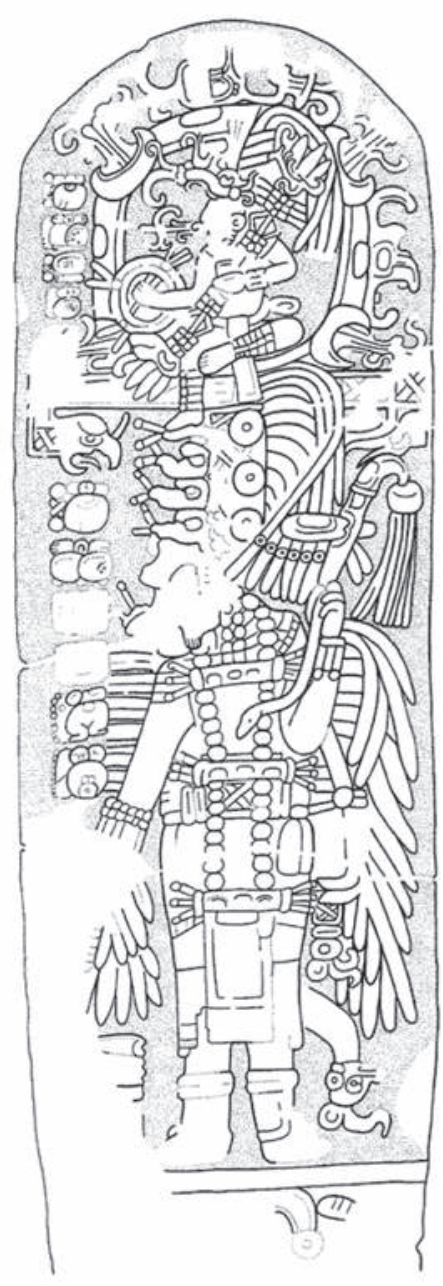




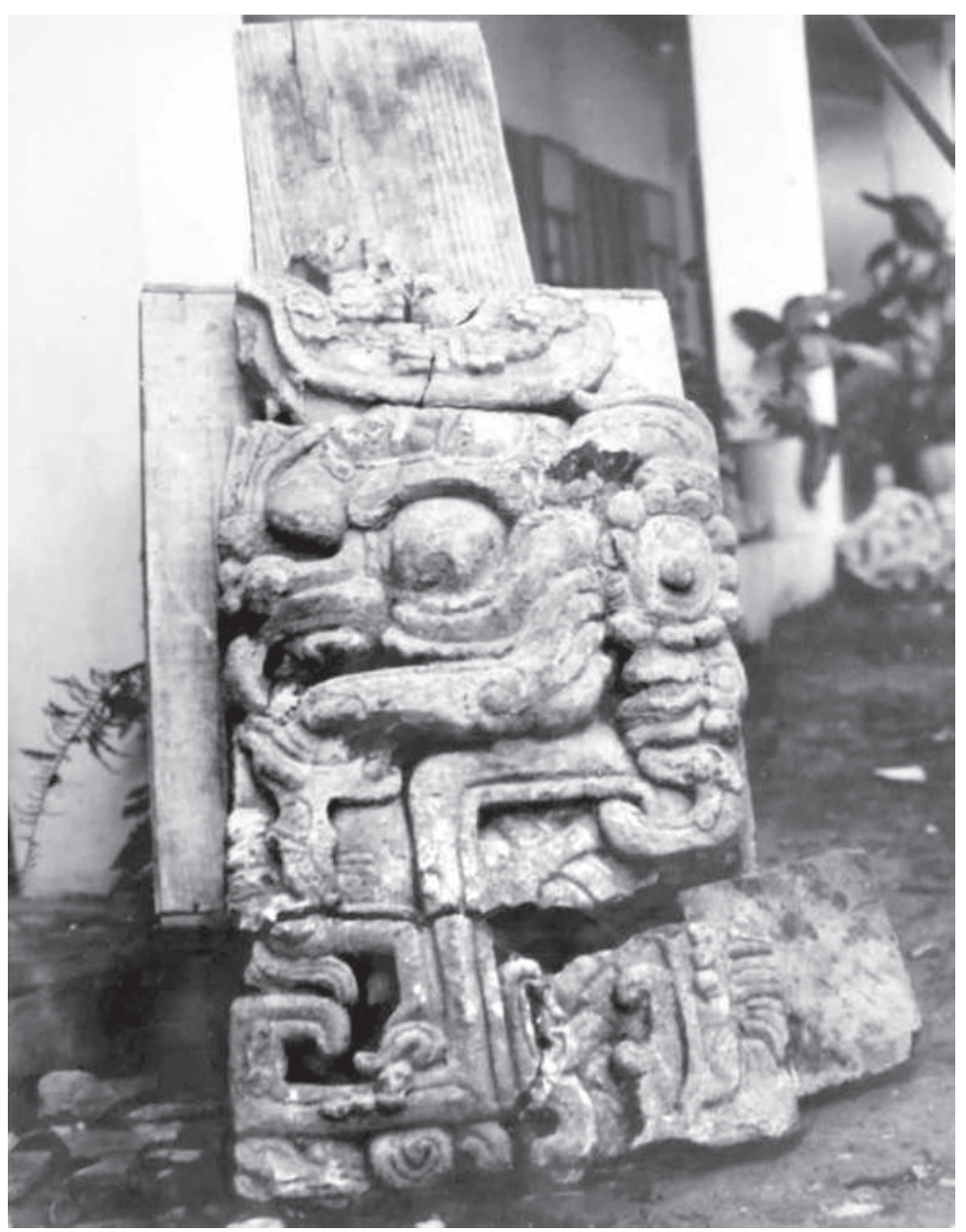

Fig. 11 - Fragmento de relieve de Natentsun, Chiapas.

Imagen tomada de Sheseña-Hernández y Tovalín-Ahumada (2014).

\section{Las aves con mandíbula de mano y con espejo en la frente en la escritura maya}

Además de su presencia dentro de las bandas celestes, estas dos aves aparecen como logogramas dentro del sistema escriturario maya, sobre todo dentro de un contexto en particular, la Cuenta Larga ${ }^{18}$. Son empleadas como representación de

18. Recientemente Valencia Rivera (2017b) ha presentado la evidencia de que el conjunto de animales que aparecen representando las diferentes unidades de tiempo dentro de la Cuenta Larga, fueron empleados para tal fin debido a que poseen la capacidad de predecir la lluvia dentro de la tradición cultural mesoamericana en general, y maya en particular. 
las unidades de tiempo de mayor magnitud dentro de esta cuenta. El ave con la mano en la mandíbula aparece como representación de los bak'tun o pih/pik y el ave con el espejo en la frente como representación de los k'atun o winik-haab ${ }^{19}$. El ejemplo más temprano donde aparecen estas dos aves en la Cuenta Larga se encuentra en la Estela 29 de Tikal (Figura 13a), cuya fecha es 8.12.14.8.15 (292 d.C.). En los ejemplos más tempranos de la Cuenta Larga, tales como las Estelas 9, 15 y 63 de Copán o las 17 y 29 de Tikal (Figuras 13b-e), ambas aves aparecen poco diferenciadas, en ocasiones compartiendo la presencia de la mano en la mandíbula, como en la Estela 63 de Copán (Figura 13d). No es sino después de la fecha 9.9.0.0.0, tal como aparece en la Estela P de Copán (Figura 13f), que el ave de los winik-haab presenta el signo de brillo en la frente que le caracterizará durante todo el resto del Clásico, como se le puede apreciar en la Estela 11 de Machaquila. El ave de los pih/pik siempre presentará la mano en la mandíbula, tal como se puede ver en el bloque procedente de un depósito localizado delante de la estructura XIII de Calakmul (Figura 13g).

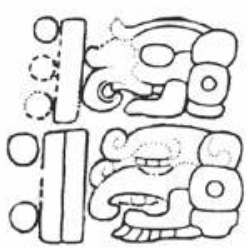

a

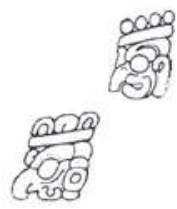

$\mathrm{e}$

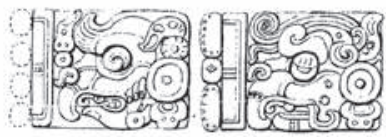

b
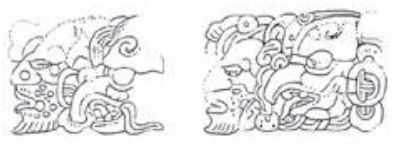

f

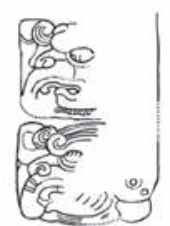

c

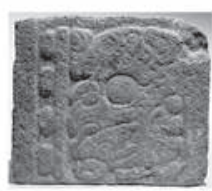

$\mathrm{g}$

Fig. 13 - a. Estela 29 de Tikal (según Jones y Satterthwaite 1982, fig. 103); b. Estela 9 de Copán, dibujo de Barbara Fash, c. Estela 15 de Copán, dibujo de Barbara Fash; d. Estela 63 de Copán, dibujo de Barbara Fash; e. Estela 6 de Tikal (según Jones y Satterthwaite 1982, fig. 86); f. Estela P de Copán (dibujo de Barbara Fash); g. Bloque de la Estructura XIII de Calakmul, fotografía de Rogelio Valencia.

19. Si bien tradicionalmente se utilizan los términos bak'tun y k'atun para denominar estos dos períodos, sabemos que sus nombres durante el período Clásico eran pih/pik para el superior, y winik-haab para el siguiente (Stuart 2011, p. 172). 
Además de este contexto, el ave con el espejo en la frente aparece como logograma dentro de otros textos y su valor de lectura ha podido ser determinado a través de su utilización en contextos muy controlados, tales como el nombre del gobernante de Dos Pilas, Bajlaj Chan K'awiil, como en el ejemplo de la Escalera Jeroglífica 4 de Dos Pilas, en el escalón IV (Figura 14a), donde el ave aparece sustituyendo al logograma de cielo, CHAN (T561) y con una complementación fonética -na. Esto nos permite asegurar que el logograma del ave con el espejo en la frente tiene un valor de lectura CHAN.

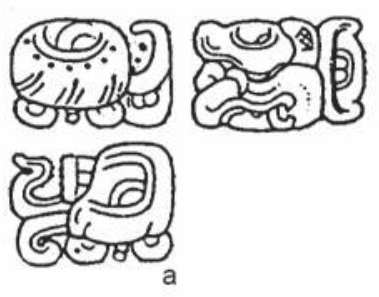

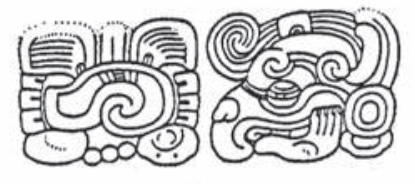

b

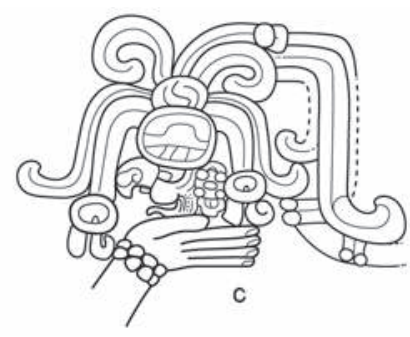

Fig. 14 - a. Escalón IV, Escalera 4 de Dos Pilas (según dibujo de Ian Graham); b. Estela 49 de Copán (según dibujo de David Stuart); c. Detalle del Friso de Placeres, Campeche. Dibujo de Daniel Salazar, basado en estudio fotográfico del autor.

Aunque poco usual, el logograma del ave con la mandíbula de mano también aparece fuera del contexto de la Cuenta Larga. Un ejemplo de su uso fuera de dicho contexto se puede ver en la Estela 49 de Copan (Figura 14b). La fecha de la Estela 49 de Copán debe ser cercana a la de la Estela Papagayo, ya que poseen un estilo de realización similar, y esta última se cree fue realizada a principios del noveno bak'tun (Law 2006, p. 62). Otro ejemplo aparece en el friso de Placeres (Figura 14c) fechado para la segunda mitad del Clásico temprano, donde el ave aparece con el glifo CHAN, "cielo", sobre la cabeza.

Pero el uso más interesante que se hace de este logograma aparece en lo que creemos es otro nicho funcional. A los pies del personaje central del friso del edificio Pimiento de Xultún (Figura 15a) se pueden apreciar dos aves: la que va junto a su pie derecho es el ave con una mandíbula de mano y junto a su pie izquierdo aparece otra ave: en este caso es un ave con un ojo trilobulado y un atado de tres nudos delante. Esta última ave opera regularmente como un logograma cuya lectura es CH'EN, “cueva, pozo" (Lacadena et al. 2010). Otro ejemplo similar es el que aparece en los murales de la Tumba 1 de Río Azul (Figura 15b): en este caso las dos aves están colocadas una encima de la otra, mostrándose en la parte superior el parpado trilobulado, en lugar de un pico se muestran dos y en la parte inferior, la mandíbula es una mano. También procedente de Río Azul tenemos una orejera realizada en jade que muestra al ave 
de la mandíbula de mano (Figura 15c), que lleva debajo el atado de tres nudos que el ave del ojo trilobulado suele llevar delante, por lo que creemos que es otro ejemplo más de esta combinación de ambos pájaros, funcionando como una conflación, tal como el ejemplo de la Tumba 1 del mismo sitio. Un último ejemplo procede de Uolantun, donde en la base de la Estela 1 (Figura 15d), fechada en 8.18.13.5.11, 6 Chuwen 14 Xul (20 de agosto de 409 d.C.) podemos apreciar al gobernante colocado sobre una banda en cuyos extremos encontramos nuevamente un par de aves, una de las cuales posee la banda con los tres nudos delante, equiparándola con la que representa al logograma $\mathbf{C H}^{\prime} \mathbf{E N}$ y la otra es un ave que, aunque no parece tener la mano en la mandíbula, ocupa el mismo lugar que ésta.

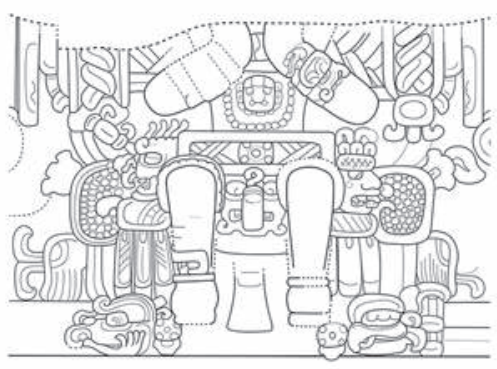

a

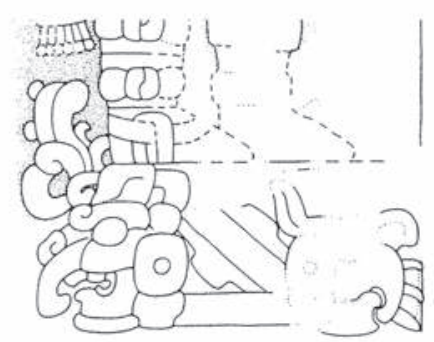

d

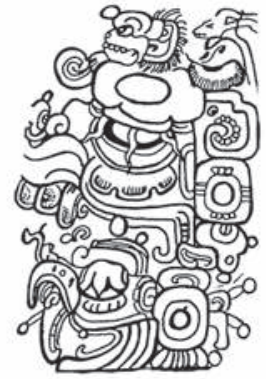

b

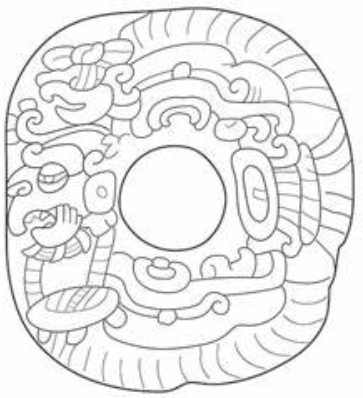

c

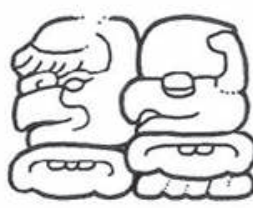

e

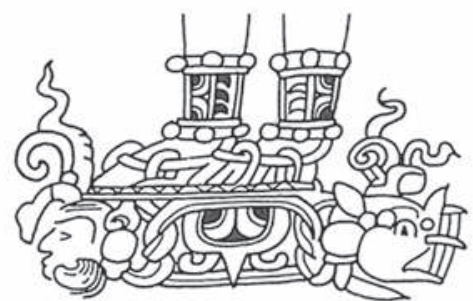

f

Fig. 15 - a. Personaje central del Friso del edificio Pimiento de Xultún. Dibujo de Daniel Salazar, basado en dibujo previo de Heather Hurst, en Saturno, Hurst y Rossi (2012); b. Detalle de la pintura mural de la Tumba 1 de Río Azul. Dibujo tomado de Hellmuth (1987); c. Orejera de jade de Río Azul. Dibujo de Daniel

Salazar, basado en fotografía presentada en Fields y Reents-Budet (2005);

d. Estela 1 de Uolantún. Según dibujo en Stuart y Houston (1994); e. Detalle del Templo XI de Copán (véase Stuart y Houston 1994, p. 11); f. Hacha de jadeíta de procedencia desconocida. Dibujo de John Montgomery, en www.famsi.org. 
Ya Acuña (2007, p. 13) presuponía que en el caso del mural de la Tumba 1 de Río Azul, ambas aves se empleaban para indicar la expresión chan-ch'e 'n, la cual fue analizado como tal por Stuart y Houston (1994, p. 11-12). De acuerdo con Hull (2011, p. 105-108) estos dos logogramas representarían un difrasismo ampliamente utilizado en las inscripciones mayas para señalar una región o, más específicamente, una comunidad. De hecho, Lacadena et al. (2010) opinan que en realidad se puede traducir como "ciudad", siendo el equivalente maya del difrasismo nahua altepetl. Existen asimismo algunos ejemplos del empleo del logograma del ave con el espejo en la frente, cuya lectura como ya indicamos es CHAN, en composición con el ave que indica el logograma CH'EN, para volver a indicar el difrasismo chan-ch'e'n, como en el Templo XI de Copán (Figura 15e; Stuart y Houston 1994, p. 11).

A pesar de que los ejemplos de empleo del ave con mandíbula de mano dentro de este contexto son tempranos, el contexto de empleo es muy uniforme, sugiriendo que son la forma temprana de empleo del difrasismo chan-ch' $e$ ' $n$, el cual durante el periodo clásico no vuelve a aparecer dentro de este nicho funcional, salvo contadas excepciones, tales como el texto Misceláneo 5 de Xcalumkin, donde aparecen combinadas ambas aves en los extremos de una banda celeste denotando el mismo difrasismo, pero sí pervive en el registro escrito empleando al ave con el espejo en la frente. Lo que esto nos sugiere es que el valor de lectura del ave con mandíbula de mano cuando se emplea como logograma sería CHAN, siendo el mismo valor de lectura asignado posteriormente al ave con el espejo en la frente. Esto explicaría porque una sustituye a la otra en el nicho funcional relacionado con las bandas celestes y que ambas, cada una en su periodo correspondiente, se emplearon para nombrar a las bandas como chan, "cielo", lo cual es completamente lógico debido a la simbología que tienen asociada.

Volviendo al ejemplo de la orejera de Río Azul (Figura 15c), éste además resulta interesante porque el ave lleva sobre la cabeza la figura de un mamífero cuyo ojo aparece anudado, indicando lo que posiblemente sea información adicional en relación al topónimo. Un ejemplo relacionado con éste, en cuanto a que posiblemente el nicho funcional aporta información adicional que detalla el lugar relacionado con el difrasismo chan-ch'e'n aparece en un hacha de jadeíta grabada (Carter 2010, p. 282-283), donde un gobernante vuelve a ser representado sobre una banda de suelo en cuyos extremos aparecen los indicadores del difrasismo chan-ch'e'n (Figura 15f). En el extremo derecho (del espectador) la banda terrestre muestra el ave $\mathbf{C H}$ 'EN, pero del lado izquierdo se muestra un rostro humano con oreja de felino y cuya mandíbula es otra vez una mano. En este caso, dicho signo se configura a partir de la conflación de un logograma de lectura desconocida y el ave con mandíbula de mano, ésta última representada únicamente por la mandíbula de mano, como un elemento pars pro toto de la versión completa. 
Si empleamos el valor de lectura CHAN para el ave con mandíbula de mano para la Estela 49 de Copán (Figura 14b), observamos que el glifo precedente es nohol, "sur", indicándonos la lectura nohol chan, "cielo del sur". No es el único caso en el que los cielos están asociados con direcciones cardinales: otro lo podemos encontrar en la vasija K688, donde se indica que la semilla del maíz nace en nah ho' chan witz xaman, "en la montaña del primero-quinto cielo, en el norte” (Valencia Rivera y García Capistrán 2013).

\section{La relación de las aves chan con las bandas celestes}

Houston y Martin (2012) han sugerido que, en la escritura maya, el signo del ave con el espejo en la frente remite de manera general a una criatura habitante del cielo, pero que también alude a un prototipo mítico de ave cuyo cuerpo y alas extendidas definen el arco celeste.

Esto no debe extrañarnos, ya López Austin (2013, p. 39-40) -entre otros muchos autores- ha mostrado cómo en la cosmovisión mesoamericana en general se tiende a personalizar las diferentes piezas de la estructura del cosmos, dotándolas en muchos casos de una naturaleza animal.

En el friso del santuario del templo de la Cruz en Palenque (Figura 16a), Tatiana Proskouriakoff (1946 [2002], p. 10-11) reconoció la presencia de un ave enmarcada por bandas celestes ${ }^{20}$. Su dibujo reconstructivo muestra un ave con marcas de espejo sobre la frente y las alas y con rasgos parecidos a los del ave chan del Clásico tardío. Además, las alas abiertas presentan bandas cruzadas que sin duda funcionan como elementos pars pro toto de una banda celeste completa ${ }^{21}$. A partir del nombre de este santuario, Wak? Chan, "Seis? Cielo", Stuart (2006, p. 109-110; también Stuart y Stuart 2008, p. 195-199) sugiere que la imaginería de este friso asocia el edificio con un simbolismo celestial. Si tomamos esta interpretación como punto de partida, una posible explicación para la presencia de esta ave en el centro de la escena es que ella misma, con sus alas extendidas, encarna el estrato celeste.

20. Dicha autora observó en los restos de estuco del friso (véase Proskouriakoff [1946] 2002, p. 10; véase también el dibujo de Maudslay que reproduce Stuart [2006, p. 110]) la ausencia de cabezas de serpiente (similares a las que lleva la Deidad Ave Principal en el pico) y otros rasgos de la deidad aviar (como el signo YAX sobre la cabeza, la diadema de cuentas y el pectoral trilobulado), por lo que reconstruyó la cabeza de esta criatura con rasgos claramente diferentes a los de las aves de los paneles del Templo de la Cruz y del Templo de la Cruz Foliada (véase Stuart y Stuart 2008, fig. 63 y 65) y del relieve de estuco de la Casa E del Palacio (Figura 5c).

21. En el arte de Palenque, la Deidad Ave Principal no lleva el motivo de las bandas cruzadas en las alas y, en general, escasea ese motivo en la iconografía de dicha ave en las tierras bajas (por ej. Dintel III del Templo IV de Tikal). Por esta razón, creemos que es altamente probable que se trate de un ave diferente, tal como lo muestra la reconstrucción de Proskouriakoff. 

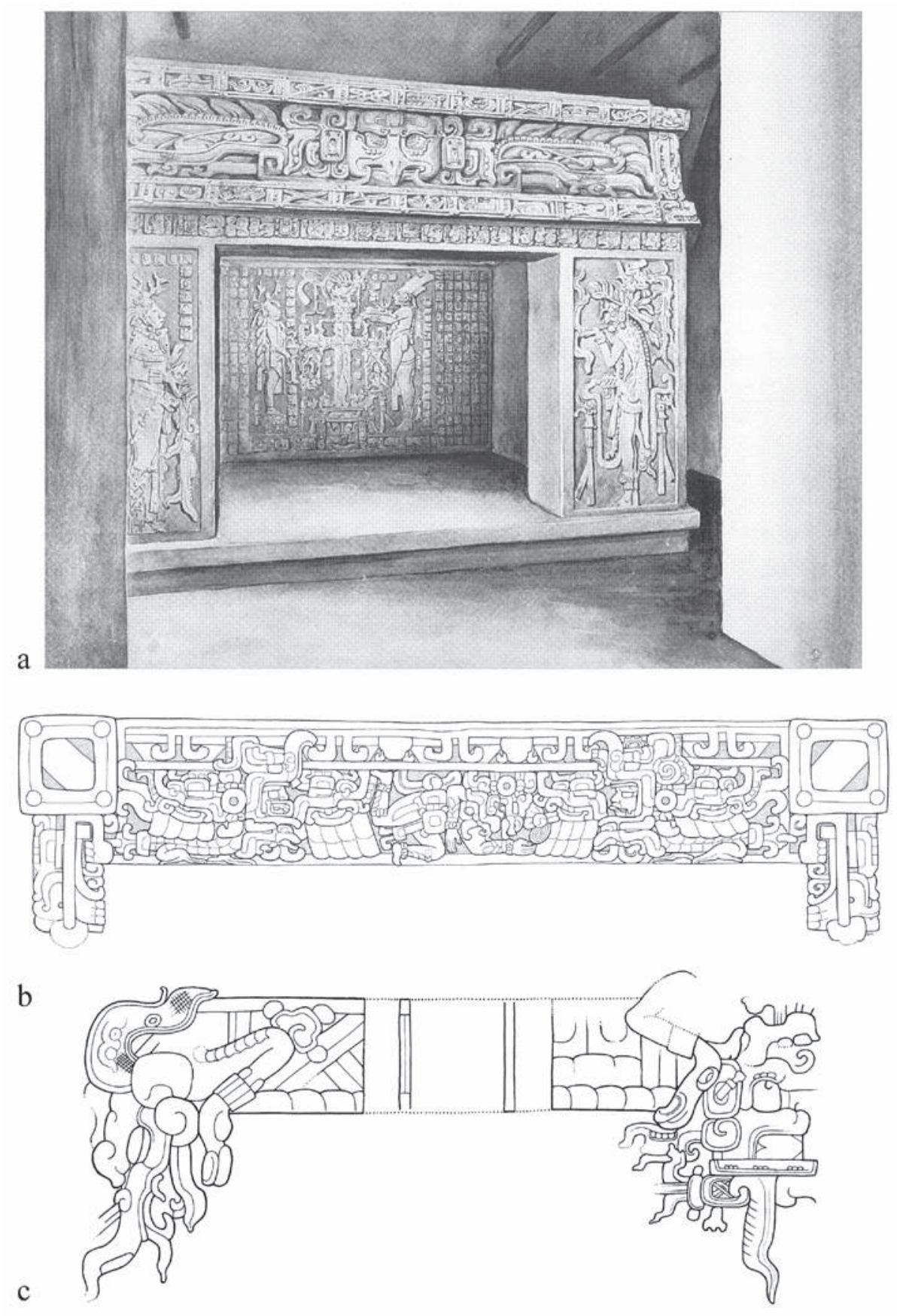

Fig. 16 - a. Reconstrucción de la fachada exterior del santuario del Templo de la Cruz, Palenque. Dibujo de Tatiana Proskouriakoff, tomado de Proskouriakoff 1946 [2002], p. 11; b. Friso de la Subestructura II C-I de Calakmul. Según dibujo de Simon Martin; c. Detalle de la Estela 11 de Piedras Negras. Según dibujo de David Stuart. 
En cuanto a las bandas celestes del Clásico temprano, no descartamos la posibilidad que dicho contenido simbólico también esté presente en el ave con mandíbula de mano, aunque en estos casos el marco celeste incorpora otros elementos, como las cabezas de serpiente (Figura 7a, c) y el cuerpo del CocodriloVenado Estelar (Figura 7b, d). Incluso, sugerimos la posibilidad de que su lectura chan puede estar íntimamente asociada con la idea del ave mítica que encarna la bóveda celeste. En otras palabras, creemos factible interpretar que en las bandas celestes las cabezas de estas aves funcionan como metonimia visual del cielo.

A su vez, esto también puede estar asociado con su presencia en la Cuenta Larga, como la representante de una gama de seres vinculados tanto al cielo como a la lluvia (Valencia Rivera 2017b).

En este mismo orden de ideas, consideramos que no es fortuito que las bandas celestes de los monumentos de Moral-Reforma, Edzná y Quiriguá (Figura 10bd) muestren dos cabezas de aves chan en sus extremos, mientras la banda celeste describe un arco, mismo que puede ser entendido como una imagen de la bóveda celeste.

Regresando brevemente a la estela de El Mesón, creemos que las cabezas de ave podrían funcionar de forma parecida, indicando con su presencia el espacio celeste sobre el que se encuentra el personaje central de la escena.

Ahora bien, en los ejemplos más tardíos, como la Estela 1 de Ek' Balam, el ave con espejo en la frente no puede ser vinculada de forma clara con tales ideas míticas, y creemos que se trata únicamente de una convención con fines prácticos, donde el ave fue perdiendo su carga simbólica en aras de una mayor funcionalidad. En el ejemplo mencionado, esta convencionalidad es notoria: el ave en el extremo de la banda celeste ya no conserva ninguna de las características formales y los rasgos diagnósticos de los ejemplos más tempranos, y únicamente se muestra como un ave "genérica" que ha perdido su carga simbólica original y el posible referente prototípico del que hablan Houston y Martin (2012).

Pese a lo que ya hemos mencionado, la asociación del ave chan con el cielo no siempre estuvo presente en la plástica maya, al menos no en las bandas celestes. En efecto, durante muchos siglos las bandas celestes incluían en sus extremos únicamente cabezas de serpientes colgantes y con rasgos estilizados (Figura 16b) o cuerpos de cocodrilos con características de otros animales (Figura 16c). Por esta razón, algunos investigadores han interpretado que para los mayas la bóveda celeste estuvo personificada por reptiles de distinta forma y naturaleza (Milbrath 1999, p. 275-282; Garza Camino 2003, p. 163-169; Stuart 2005, p. 71-75; López Austin 2013, p. 39-40). Tal vez se trate de una herencia olmeca (por ejemplo Estela 3 de Tres Zapotes; pintura rupestre en la cueva de Oxtotitlán, Guerrero. Consultar Taube 1995), también presente de manera abundante en los monumentos preclásicos de los sitios de la costa del Pacífico (por ejemplo altares 12 y 13 de Takalik Abaj; Estelas 7, 18, 23, 26 de Izapa; escultura 14 de Kaminaljuyú). 
De ser cierta nuestra interpretación acerca de la carga simbólica de las cabezas de ave chan en las bandas celestes, esto implicaría que hacia los inicios del Clásico temprano -cuando aparecen por primera vez en la iconografía mayase da un ligero cambio en la concepción del estrato celeste, y éste comienza a adquirir una naturaleza y un aspecto aviar. En estos casos, la continuidad en la inclusión de cabezas de serpientes y del Cocodrilo-Venado Estelar (como en el mascarón de Bayal en Xultún y en los relieves de Margarita y Macizo en Copán) podría responder a necesidades narrativas, siendo estas criaturas claras alusiones a episodios míticos que tuvieron como marco espacial el cielo.

Al respecto, es importante subrayar que los cambios experimentados en el uso de las distintas aves chan dentro del sistema de escritura maya se ven reflejados en los contextos iconográficos con la sustitución del ave con mandíbula de mano por el ave con el espejo en la frente, y por el importante ejemplar de Natentsun - probablemente de inicios del Clásico tardío- que constituye un claro caso de transición entre ambos signos. Este comportamiento cronológico compartido entre la escritura y la imaginaría maya acusa a su vez el estrecho vínculo existente entre ambos sistemas de comunicación y refuerza la idea de una relación complementaria.

\section{Discusión y comentarios finales: interpretación integral de las cabezas de aves chan en las bandas celestes}

Para poder comprender la función de estas dos aves dentro del contexto iconográfico de las bandas celestes y acercarnos a proponer una interpretación integral, queremos antes remarcar dos aspectos importantes.

En primer lugar, todos los casos de esculturas con cabezas de aves integradas en bandas celestes que hemos registrado se ubican en espacios públicos o semi públicos, ya sea en las fachadas de los edificios y de frente a patios o amplias plazas (por ejemplo programas escultóricos de Margarita, Macizo y Yehnal en Copán, mascarones de Bayal en Xultún, relieves de Toniná, Dzibanché y posiblemente Natentsun), o como esculturas exentas inmersas en dichos espacios, como los monumentos de Moral-Reforma y Edzná y las estelas de Naranjo, Quiriguá y Ek' Balam. Esta ubicación recurrente nos indica que los monumentos conforman un tipo de comunicación visual destinada a la transmisión de mensajes a distintos grupos sociales reunidos en los espacios públicos, cada uno con diversos grados de especialización y niveles de entendimiento de las imágenes y sus componentes. Al respecto, varios investigadores (Kubler 1969, p. 48; Fash y Fash 1996, p. 127; von Schwerin 2011; WernessRude y Spencer 2015, p. 43-46, 49-52) han observado que las imágenes de estos contextos son particularmente estables, repetitivas y constantes a través del tiempo, logrando así la efectiva comunicación de un discurso específico. 
Íntimamente asociado con esta idea, el segundo aspecto que queremos resaltar es el alto grado de iconicidad de los signos de ave incorporados en las bandas celestes. Si bien estos signos no remiten a criaturas reales e integran elementos y rasgos que no corresponden con un aspecto natural, consideramos que tales características responden a una construcción convencional. En ese sentido, coincidimos con Goodman (2010, p. 21-25) cuando plantea que la representación y la figuración se asocian a la reconstrucción más que a la reproducción o copia; por lo que el concepto de semejanza entre el signo icónico y su referente se fundamenta sobre bases convencionales y es aprendido culturalmente. Así, a pesar de que los signos de aves pertenecen a un sistema de escritura no accesible a todos los grupos sociales (consultar Houston y Stuart 1992, p. 592), su alto grado de iconicidad, sumado a la repetividad, constancia y estabilidad a través del tiempo, son factores que posiblemente permitieron su identificación, así como su reconocimiento como parte del conjunto de elementos empleados en la representación de los espacios celestes.

Recientemente Werness-Rude y Spencer (2015, p. 56) han planteado que durante el Clásico maya la imagen y la escritura tuvieron el potencial de desarrollar principios complementarios. En los ejemplos mencionados al inicio de este trabajo vimos cómo esta complementariedad configura un complejo sistema de comunicación visual donde los elementos jeroglíficos especifican y definen lo que las imágenes solas a veces no alcanzan a mostrar de manera efectiva.

Tomando esta premisa como punto de partida, proponemos que una de las funciones de las aves integradas en las bandas celestes es favorecer el nivel denotativo de las imágenes. Al respecto, relacionamos el nivel denotativo con la identificación o el reconocimiento de los elementos que componen una escena (Barthes 1986; Carrere y Saborit 2000, p. 121-123; Goodman 2010, p. 19-21).

Esta interpretación acerca del papel de las cabezas de ave en contextos iconográficos se sustenta en el alto grado de iconicidad del signo y en su lectura chan, "cielo". Creemos que, al igual que los signos que componen las bandas celestes ( $k$ 'in, ek', chan, etc.), y actuando en conjunto con estos elementos, las cabezas de ave definen la representación de un espacio cosmológico de forma inequívoca. En estos casos, las cabezas del ave chan no son simples objetos colocados de forma arbitraria dentro de las imágenes; se trata de elementos complementarios que adquieren un valor enfático y un significado dentro del contexto (consultar Valencia Rivera 2015) ${ }^{22}$.

Dentro del corpus de casos analizados, un claro ejemplo del papel denotativo de las aves chan se ve en el mascarón de Bayal en Xultún (Figura 7a). En esta imagen, la sección horizontal de la banda celeste -la que contiene en otros ejemplares los signos estelares- se encuentra completamente oculta por la

22. Para una discusión más detallada sobre esta idea dentro del arte mesoamericano en general, consultar el artículo "History of art and anthropology of art" de Claude Baudez (2002). 
parte superior de un árbol, y su presencia (y por ende la correcta identificación del entorno representado) se infiere únicamente por las aves en sus extremos.

Adicionalmente, consideramos que la elección de las cabezas de ave para los espacios celestes se puede explicar bajo un principio metonímico; es decir, que dichas cabezas funcionan como elementos pars pro toto que remiten a la totalidad del cielo y cuyos orígenes pueden tener fundamentos mitológicos acerca del ave como la encarnación misma del estrato celeste.

Planteamos que ambas funciones - denotativa y metonímica- no son excluyentes; se trata más bien de dos dimensiones en las que opera el signo del ave chan en las bandas celestes. Con este ejemplo observamos cómo la integración de elementos de escritura en las imágenes genera una efectiva complementariedad semántica, favoreciendo la comunicación y la comprensión del mensaje contenido.

Al hilo de esta idea, y tomando en cuenta la naturaleza pública de los monumentos en los que se registra la presencia de estas aves, creemos que un espectador con un grado medio o bajo de conocimiento práctico sobre la escritura y el complejo iconográfico utilizado, podría en todo caso identificar al ave y/o a las bandas celestes. Así, la correcta identificación del espacio celestial, que deriva en la reducción de la ambigüedad del mensaje contenido, se lograría a través de la congruencia y complementariedad entre ambos componentes.

Así descrita, la integración de elementos de escritura en las imágenes constituye un sistema significante fuertemente codificado. Carrere y Saborit (2000, p. 79-81) denominan a este tipo de sistemas como "código duro", al cual definen de la siguiente forma:

[...] código duro es aquel en el que el signo [visual] presenta una segmentación precisa en sus unidades expresivas, el contenido resulta igualmente nítido y la relación entre ambos es estable, dando lugar a mayores certezas en la comunicación y ausencia de polisemia o múltiple interpretación. (Carrere y Saborit 2000, p. 80)

Esta preocupación de los artistas mayas por favorecer el reconocimiento icónico de los elementos componentes de una imagen puede expresarse por otros medios. Las llamadas "máscaras de rayos X", que dejan ver debajo el rostro de quienes las portan, son, como lo considera Erik Velásquez García (2007), artilugios visuales que promueven la correcta identificación de los personajes (por ejemplo Estela 11 de Yaxchilán, Figura 17a). La transparencia de algunos sacos, que permite ver el interior lleno de semillas (por ejemplo tapas de bóveda $\mathrm{N}^{\circ} 1$ y 6 de Dzibilnocac, Campeche, Figura 17b y c; tapa de bóveda $N^{\circ} 7$ de Xkichmook, Yucatán, Figura 17d), es otra solución gráfica a la misma problemática.

Consideramos que la integración y la interacción de elementos jeroglíficos en contextos iconográficos es una de las estrategias comunicativas utilizadas por los artistas mayas y por los grupos de élite involucrados en la creación de los programas escultóricos, cuya finalidad es la construcción de imágenes que 


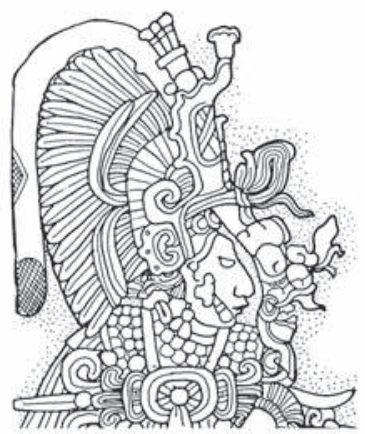

a

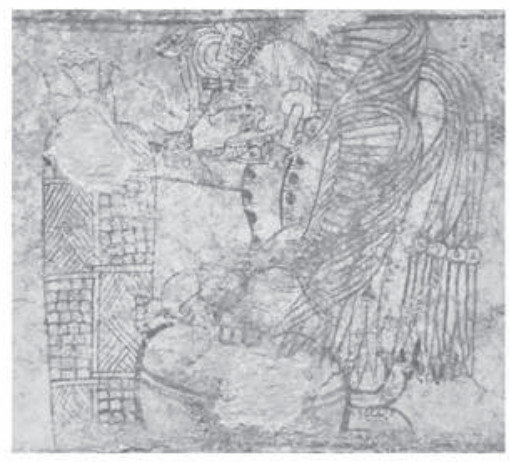

c

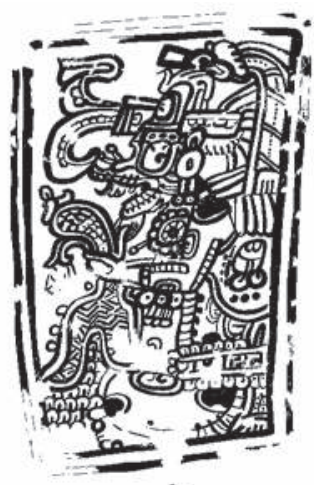

b

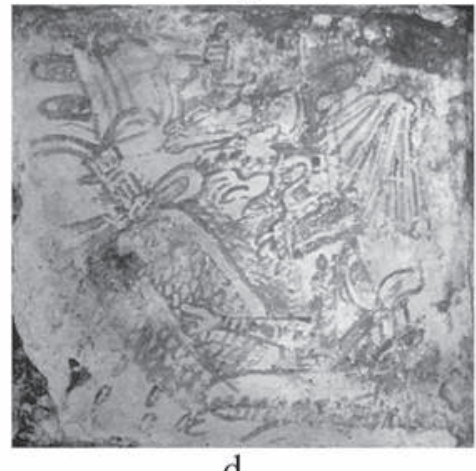

d

Fig. 17 - a. Estela 11 de Yaxchilán. Dibujo de Linda Schele, en www.famsi. org; b. Tapa de bóveda n. ${ }^{\circ} 1$ de Dzibilnocac. Dibujo de Christian Prager, en www.wayeb.org; c. Tapa de bóveda n. ${ }^{\circ} 6$ de Dzibilnocac (fotografía Rogelio Valencia); d. Tapa de bóveda n. ${ }^{\circ} 7$ de Xkichmook (fotografía Leticia Staines).

logren expresar contenidos de forma clara, enfatizando o definiendo aquellos aspectos que no se pueden mostrar en imágenes, reduciendo de esta manera el grado de ambigüedad que pueda tener una representación gráfica. *

* Manuscrit reçu en juin 2016, accepté pour publication en février 2017.

Agradecimientos - Agradecemos a Dominique Michelet por su interés en este trabajo, por sus comentarios y sugerencias, y por la revisión que hizo del texto. También agradecemos a Luz Evelia Campaña por darnos acceso a la información de los relieves del Templo I de Dzibanché y por brindarnos las fotografías de los restos de estuco hechas al momento de su descubrimiento; sus imágenes permitieron realizar el dibujo que aquí presentamos. Por último, deseamos agradecer a los dictaminadores anónimos de este escrito por sus valiosas sugerencias. 


\section{Referencias citadas}

ACuÑa Mary Jane

2007 Ancient Maya cosmological landscapes. Early Classic mural painting at Río Azul, Peten, Guatemala, tesis de maestría en Artes, University of Texas, Austin.

BARDAWIL Lawrence

1976 "The principal bird deity in Maya art. An iconographic study of form and meaning", in Merle G. Robertson (ed.), The art, iconography and dynastic history of Palenque, Part III. Proceedings of the segunda mesa redonda de Palenque, December 14-21, 1974, Palenque, Pre-Columbian Art Research, San Francisco, p. 195-209.

BARThel Thomas S. y Hasso Von Winning

1991 “La Mojarra Stela 1 Revisited”, Tribus, 40, p. 43-82.

BARTHES Roland

1986 "Retórica de la imagen", in Roland Barthes (com.), Lo Obvio y lo Obtuso. Imágenes, gestos, voces, Editorial Paidós, Barcelona.

BAUdEz Claude-François

2002 "History of art and anthropology of art", RES Anthropology and Aesthetics, 42, p. 139-141.

BeCQueLin Pierre

1995 "L'axe vertical dans la cosmologie maya", Trace, 28, p. 53-59.

Campaña Valenzuela Luz Evelia

1995 "Una tumba en el Templo del Búho, Dzibanché”, Arqueología mexicana, 3 (14), p. 28-31.

CARlson John B. y Linda C. Landis

2000 "Bandas, dragones bicéfalos y otros animales míticos: la banda celeste en el arte y la iconografía maya", in Silvia Trejo (ed.), Mesas redondas de Palenque. Antología, Conaculta/INAH, México, vol. II, p. 255-274.

CARrere Alberto y José SABorit

2000 Retórica de la Pintura, Cátedra (Signo e Imagen, 59), Madrid.

CARTER Nicholas

2010 "Celt with a Ruler", in Daniel Finamore y Stephen Houston (eds), Fiery pool. The Maya and the mythic sea, Peabody Essex Museum, Salem/Yale University Press, New Haven, p. 282-283.

Dienl Richard y Michael Coe

1995 "Olmec Archaeology", in Jill Guthrie y Elizabeth Benson (eds), The Olmec World. Ritual and Rulership, The Art Museum, Princeton University, New Jersey, p. 10-25.

FASH William y Barbara FASH

1996 "Building a world view. Visual communication in Classic Maya architecture", RES Anthropology and Aesthetics, 29-30, p. 127-147.

Fash Barbara, William Fash, Jorge Ramos y Alexandre Tokovinine

2014 Informe del Centro David Rockefeller de estudios Latinoamericanos, programa Banco Santander/Fundación Botín para la Investigación y Conservación de la Escultura Maya, reporte de actividades realizadas en 2013, entregado a President and Fellows of Harvard College, Boston. 
Fields Virginia y Dorie ReEnts-Budet (eds)

2005 Los Mayas. Señores de la Creación. Los Orígenes de la Realeza Sagrada, Editorial Nerea, San Sebastián (España).

García Barrios Ana

2015 "El mito del diluvio en las ceremonias de entronización de los gobernantes mayas. Agentes responsables de la decapitación del saurio y nuevas fundaciones", Estudios de Cultura Maya, 45, p. 11-48.

Garza CAmino Mercedes de la

2003 El universo sagrado de la serpiente entre los mayas, UNAM, Instituto de Investigaciones Filológicas, Centro de Estudios Mayas, México.

Goodman Nelson

2010 Los lenguajes del arte. Aproximación a la teoría de los símbolos, Editorial Paidós, Madrid.

Hellmuth Nicholas

1987 Monster und Menschen in der maya Kunst, Akademische Druck, Graz.

Henderson Lucia

2013 Bodies politic, bodies in stone. Imagery of the human and the divine in the sculpture of late Preclassic Kaminaljuyú, Guatemala, tesis doctoral en historia del arte, University of Texas, Austin.

Houston Stephen D.

2004 "Writing in early Mesoamerica", in Stephen D. Houston (ed.), The first writing. Script invention as history and process, Cambridge University Press, Cambridge, p. 274-309.

Houston Stephen D. y Simon Martin

2012 "Mythic prototypes and Maya writing", texto publicado en Maya Decipherment, 4 de enero de 2012, http://decipherment.wordpress.com/2012/01/04/ mythic-prototypes-and-maya-writing/, página consultada en el 24/11/2017.

Houston Stephen D. y David StuarT

1992 “On Maya hieroglyphic literacy”, Current Anthropology, 33 (5), p. 589-593.

1998 "The Ancient Maya self: personhood and portraiture in the Classic period", RES Anthropology and Aesthet, 33, p. 73-101.

Hull Kerry M.

2011 "Poetic tenacity: a diachronic study of kennings in Mayan languages", Parallel worlds. Genre, discourse, and poetics in contemporary, colonial, and classic Maya literature, Kerry M. Hull y Michael D. Carrasco (eds), University Press of Colorado, Colorado, p. 73-122.

Jones Christopher y Linton SATTERTHWAite

1982 The monuments and inscriptions of Tikal: the carved monuments, University of Pennsylvania Museum of Archaeology and Anthropology (Tikal reports, 33; University Museum monograph, 44), Philadelphia.

KAPLAN Jonathan

2000 "Monument 65: a great emblematic depiction of throned rule and royal sacrifice at late preclassic Kaminaljuyu", Ancient Mesoamerica, 11 (2), p. 185-198.

Kelley David H.

1982 "Costume and name in Mesoamerica", Visible Language, 16 (1), p. 39-48. 
Kettunen Harri y Christophe Helmke

2013 "Water in Maya imagery and writing", Contributions in New World Archaeology, 5, p. 17-38.

2014 Introduction to Maya hieroglyphs, Wayeb/Comenius University in Bratislava/ The Slovak Archaeological and Historical Institute, Bratislava.

KUBler George

1969 Studies in Classic Maya iconography, Connecticut Academy of Arts and Sciences, New Haven.

LaCAdena García-Gallo Alfonso

2003 El corpus glifico de Ek’ Balam, Yucatán, México, informe presentado a FAMSI, http://www.famsi.org/reports/01057es/01057esLacadenaGarciaGallo01.pdf, consultado el 27/11/2017.

2008 "Epigrafía en Ek' Balam", informe presentado en "VI Mesa redonda de Palenque" [Palenque, 16 al 21 de noviembre].

Lacadena García-Gallo Alfonso, Sebastian Matteo, Asier Rodríguez Manjavacas, Hugo García CAPISTRÁn, Rogelio Valencia Rivera y Ignacio CASEs Marín

2010 Introducción a la escritura jeroglífica maya. Cuaderno de Trabajo 2, talleres de escritura jeroglífica maya presentado en " $15^{\text {a }}$ Conferencia Maya Europea" [Museo de América de Madrid, 30 de noviembre-2 de diciembre de 2010].

LAw Daniel A.

2006 A grammatical description of the Early Classic Maya hieroglyphic inscriptions, tesis de Maestría en Artes, Department of Linguistics and English Language, Brigham Young University, Provo.

LóPez Austin Alfredo

1997 "El árbol cósmico en la tradición mesoamericana", Monografias del Jardín botánico de Córdoba, 5, p. 85-98.

2013 "La fauna maravillosa de Mesoamérica (una clasificación)", in Luis Millones y Alfredo López Austin (eds), Fauna fantástica de Mesoamérica y los Andes, UNAM, Instituto de Investigaciones Antropológicas, México, p. 31-92.

Martin Simon

2015 "The old man of the Maya universe: unified aspects to Ancient Maya religion", in Charles Golden, Stephen Houston y Joel Skidmore (eds), Maya Archaeology 3, Precolumbian Mesoweb Press, San Francisco, p. 186-226.

MAYER Karl Herbert

1989 Maya monuments: sculptures of unknown provenance. Supplement 2, Verlag Von Flemming, Berlin.

Milbrath Susan

1999 Star gods of the Maya. Astronomy in art, folklore, and calendars, University of Texas Press, Austin.

Miller Mary y Karl TAube

2011 The gods and Symbols of ancient México and the Maya. An Illustrated dictionary of Mesoamerican religión, Thames \& Hudson, London.

Nielsen Jesper y Toke SELlner ReunerT

2015 "Estratos, regiones e híbridos. Una reconstrucción de las cosmología mesoamericana", in Ana Díaz (coord.), Cielos e inframundos. Una revision de las 
cosmologías mesoamericanas, UNAM, Instituto de Investigaciones Históricas, México, p. 25-64.

PARSONS Lee Allen

1986 The origins of Maya art: monumental stone sculpture of Kaminaljuyu, Guatemala, and the southern Pacific coast, Dumbarton Oaks Research Library and Collection (Studies in pre-Columbian art \& archaeology, 28), Washington (DC).

Proskouriakoff Tatiana

2002 [1946] An album of Maya architecture, Dover Publications, Mineola/New York. QUIRARTE Jacinto

1974 "Terrestrial/celestial polymorphs as narrative frames in the art of Izapa and Palenque", in Merle G. Robertson (ed.), Primera Mesa Redonda de Palenque, Part I. A conference on the art, iconography, and dynastic history of Palenque, Robert Louis Stevenson School/Pre-Columbian Art Research, Pebble Beach, p. 129-135.

ROBERTSON Merle Greene

1985 The sculpture of Palenque, vol. III. The late buildings of the palace, Princeton University Press, Princeton.

Salazar Lama Daniel

2014 Montañas, antepasados y escenas de resurrección en el friso de Balamkú, Campeche, tesis de maestría en Estudios Mesoamericanos, UNAM, México.

2015 "Formas de sacralizar a la figura real entre los mayas", Journal de la Société des américanistes, 101 (1-2), p. 11-49.

Salazar Lama Daniel y Rogelio Valencia Rivera

2017 "The Written Adornment: the many relations of texts and image in the Classic Maya visual culture", Visible Language, 51 (2), p. 80-115.

SAturno William, Heather Hurst y Franco Rossi

2012 “Observaciones preliminares sobre la iconografía de la Acrópolis Los Árboles (12F19), Xultun", in Patricia Rivera Castillo y William Saturno (eds), Proyecto arqueológico regional San Bartolo-Xultún. Informe de resultados de investigaciones de la temporada de campo no. 11, año 2012, informe entregado al Instituto de Antropología e historia de Guatemala, Ciudad de Guatemala.

SCHELE Linda y David FreIDEL

2000 Una selva de reyes. La asombrosa historia de los antiguos Mayas, Fondo de Cultura Económica, México.

SEgovia Pinto Víctor

1981 "Kohunlich: una ciudad maya del Clásico temprano", in Arturo Romano Pacheco, Carlos Navarrete y Victor Segovia Pinto (eds), Kohunlich: una ciudad maya del Clásico Temprano, San Ángel Ediciones S.A., México, p. 211-295.

Sheseña Hernández Alejandro y Alejandro Tovalín Ahumada

2014 "Los sitios arqueológicos de Chilón, Nachoj, Mukana y Natentsun, municipio de Chilón, Chiapas", Liminar. Estudios Sociales y Humanísticos, 12 (1), p. 53-64.

Stone Andrea y Marc Zender

2011 Reading Maya art. A hieroglyphic guide to ancient Maya painting and sculpture, Thames \& Hudson, London. 
STUART David

2006 Sourcebook for the 30th Maya meetings, Mesoamerican Center/Department of Art and Art History, University of Texas, Austin.

2010 Comentarios sobre las inscripciones del Templo XIX de Palenque, producido, diseñado y editado por Joel Skidmore, Chip Breitwieser y Dawn Glenn, para Precolumbia Mesoweb Press, Pre-Columbian Art Research Institute, San Francisco.

2011 The order of days. The Maya world and the truth about 2012, Harmony Books, New York.

StUART David y George STUART

2008 Palenque. Eternal city of the Maya, Thames \& Hudson, London.

Stuart David y Stephen Houston

1994 Classic Maya place names, Dumbarton Oaks Research Library and Collection (Studies in pre-Columbian art and archaeology, 33), Washington (DC).

TAUBE Karl

1995 "The rainmakers: the Olmec and their contribution to Mesoamerican belief and ritual", in Jill Guthrie (ed.), The Olmec world. Ritual and Rulership, Art Museum/Princeton University, New Jersey, p. 83-103.

TAube Karl y Stephen Houston

2015 "Masks and iconography", in Stephen Houston, Sarah Newman, Edwin Román y Thomas Garrison (eds), Temple of the night sun. A royal tomb at El Diablo, Guatemala, Precolumbia Mesoweb Press, San Francisco, p. 208-225.

Taube Karl, William Saturno, David Stuart y Heather Hurst

2010 "Los murales de San Bartolo, El Petén, Guatemala, parte 2, El mural poniente", Ancient America, 10, p. 1-111.

Tokovinine Alexandre

2013 3D imaging report. Peabody Museum's Corpus of Maya hieroglyphic inscriptions program (CMHI), https://www.peabody.harvard.edu/node/821, consultado el 27/11/2017.

URCID Javier y Arthur JOYCE

2014 "Early transformations of Monte Albán's Main Plaza and their political implications", in Kenichiro Tsukamoto y Takeshi Inomata (eds), Mesoamerican plazas. Arenas of community and power, University of Arizona Press, Tucson, p. 149-167.

VALENCIA Rivera Rogelio

2015 “A picture is worth a thousand words. Or is it?", in Harri Kettunen y Christophe Helmke (eds.), On methods. How we know what we think we know about the Maya, Verlag Anton Saurwein, München, p. 91-100.

2017a "The Maya abundance god K'awiil and his Mesoamerican counterparts", conferencia presentada en "Maya Meetings 2017 Symposium, Tlillan Tlapallan: The Mayas as Neighbors in Ancient Mesoamerica" [University of Texas at Austin, enero 13-14, 2017].

2017b "El tiempo vuela: el uso de aves y otros animales para representar las unidades de tiempo en la Cuenta Larga maya", Journal de la Société des américanistes, Hors-série, p. 335-366. 
Valencia Rivera Rogelio y Hugo García Capistrán

2013 "In the place of the mist: analyzing a Maya myth from a Mesoamerican perspective", in Jesper Nielsen y Christophe Helmke (eds.), The Maya in a Mesoamerican context. Comparative approaches to Maya studies, Verlag Anton Saurwein, Markt Schwaben, p. 35-50.

VelÁSQuez García Erik

2006 "The Maya flood myth and the decapitation of the cosmic caiman", The PARI Journal, 7 (1), p. 1-10, www.mesoweb.com/pari/publications/journal/701/ Flood_e.pdf, consultado el 27/11/2017.

2007 "La máscara de 'rayos X'. Historia de un artilugio iconográfico en el arte maya", Anales del Instituto de Investigaciones Estéticas, 90, p. 7-36.

Von SCHWERIN Jennifer

2011 "The sacred mountain in social context. Symbolism and history in Maya architecture: Temple 22 at Copan, Honduras", Ancient Mesoamerica, 22 (2), p. 271-300.

Werness-Rude Maline D. y Kaylee R. SPEncer

2015 "Imagery, architecture, and activity in the Maya world: an Introduction", in Maline D. Werness-Rude y Kaylee R. Spencer (eds), Maya imagery, architecture, and activity space and spatial analysis in Art History, University of ZENDER Marc New Mexico Press, Albuquerque, p. 1-105.

2004 “Glyphs for 'handspan' and 'strike' in Classic Maya ballgame texts", The PARI Journal, 4 (4), p. 1-9. 
